\title{
Assess the Performance against ETS and PM1 and Evaluate the Users' Experiences of Comfort of Nasal Filters
}

Ibrahim Almuhaidib

iaalmuhaidib@mix.wvu.edu

Follow this and additional works at: https://researchrepository.wvu.edu/etd

Part of the Industrial Engineering Commons

\section{Recommended Citation}

Almuhaidib, Ibrahim, "Assess the Performance against ETS and PM1 and Evaluate the Users' Experiences of Comfort of Nasal Filters" (2020). Graduate Theses, Dissertations, and Problem Reports. 7699.

https://researchrepository.wvu.edu/etd/7699

This Dissertation is protected by copyright and/or related rights. It has been brought to you by the The Research Repository @ WVU with permission from the rights-holder(s). You are free to use this Dissertation in any way that is permitted by the copyright and related rights legislation that applies to your use. For other uses you must obtain permission from the rights-holder(s) directly, unless additional rights are indicated by a Creative Commons license in the record and/ or on the work itself. This Dissertation has been accepted for inclusion in WVU Graduate Theses, Dissertations, and Problem Reports collection by an authorized administrator of The Research Repository @ WVU.

For more information, please contact researchrepository@mail.wvu.edu. 


\title{
Assess the Performance against ETS and PM 1 and Evaluate the Users' Experiences of Comfort of Nasal Filters
}

\author{
IBRAHIM ALMUHAIDIB \\ Dissertation submitted to \\ Benjamin M. Statler College of Engineering and Mineral Resources \\ At West Virginia University \\ in partial fulfillment of the requirements for the degree of \\ Doctor of Philosophy \\ in \\ Occupational Safety and Health \\ Warren Myers, Ph.D., Chair \\ Gary L. Winn, Ph.D. \\ Kenneth Currie, Ph.D. \\ Ziqing Zhuang, Ph.D. \\ Anna Allen, MD. \\ Department of Industrial and Management Systems Engineering
}

\section{Morgantown, West Virginia}

2020

Keywords: Air pollution, Particulate Matter, Environmental Tobacco Smoke, Efficiency, Nasal Filters, Flow Rates.

Copyright 2020 Ibrahim Almuhaidib 


\section{Abstract \\ Assess the Performance against ETS and PM1 and Evaluate the Users' Experiences of Comfort of Nasal Filters \\ Ibrahim Almuhaidib}

Many cities around the world experience severe air pollution. According to the World Health Organization (WHO), 7 million people die annually from exposure to small airborne Particulate Matter (PM) that is found in atmospheric pollution. Particulate matter in atmospheric pollution is one of six classifications of common air pollutants and is typically referenced to as $\mathrm{PM}_{1}$ and $\mathrm{PM}_{2.5}$. Particulate designated as $\mathrm{PM}_{1}$ and $\mathrm{PM}_{2.5}$ refer to particles having aerodynamic diameters of 1 or 2.5 micrometer $(\mu \mathrm{m})$, respectively. These size ranges of particles are the most commonly found in air pollution. It is hard to differentiate these particles while in the air, and this poses a threat to human health. Researchers have developed various types of aerosol sampling techniques to help measure and differentiate these different size particles.

One potential means to help minimize personal exposure to particulate air pollution is the use of nasal filters. A few studies have been conducted on nasal filters to determine their effectiveness in reducing pollen allergy reactions. However, no studies have been found that have evaluated the comfort of wearing nasal filters or their filtration efficiency against particle sizes found in air pollution.

The main purpose of this research is to measure the efficiency of five new models of nasal filters against two aerosol challenges and to determine user comfort by performing various tasks (turning the head side to side, moving the head up and down, normal breathing, deep breathing, bending over, and walking) while exposed to different types and sizes of particulate.

The efficiency of these nasal filters has been evaluated against environmental tobacco smoke (ETS) and $\mathrm{PM}_{1}$ size particulate at different flow rates and concentrations. User perception 
and acceptability were assessed on six subjects performing different tasks conducted inside and outside of the Respiratory Laboratory on the West Virginia University campus. After completing all tasks, participants were asked to complete a survey about several categories associated with comfort of the nasal filters. Results of the research will be useful to nasal filter manufacturers, researchers, and users. The approval of the Institutional Review Board (IRB) at the University of West Virginia was obtained and the protocol number is 1906614987. 


\section{Acknowledgements}

First and foremost, I would like to thank God Almighty for giving me strength, understanding, knowledge and the ability to complete the research study. Without his blessings and mercy, the research study would not have been possible. Second, I would like to express my deepest gratitude to my advisor Dr. Warren Myers for support, encouragement, and guidance. His invaluable recommendations and his tremendous and continuous academic support helped me overcome many of the obstacles I encountered in the research. This research could not be completed without his endless and frequent help. Third, I would thank Dr. Xinjian (Kevin) He. I am grateful and indebted to him for his academic support and help during my research development and writing.

Also, I would like to express my deepest appreciation to my advisory committee: Dr. Gary Winn, Dr. Kenneth Currie, Dr. Ziqing Zhuang, and Dr. Anna Allen for their insightful comments and valuable suggestions throughout this research. I would also like to thank my colleagues in the respiratory laboratory for their support and excellent cooperation.

I would like to express my deep and sincere gratitude to my family for their unparalleled love, support, and for their faith in me. I am forever thankful and indebted to my parents for their support and encouragement throughout my study journey. To my wife and my two lovely daughters your love, support, and understanding helped me through this journey. Without you believing in me, I never would have completed this dissertation. Also, I am grateful to my siblings for invaluable support and love.

Finally, Special thanks to my country, Saudi Arabia, for its financial support to me during my master's and PhD studies. Without this financial support, I would not have been able to come 
and study in the United States. I ask God to return the favor and seek the advancement of my country by applying what I learned in my studies outside the country. 


\section{Introduction}

Approximately $91 \%$ of urban dwellers worldwide are exposed to air that exceeds pollution guidelines set by the World Health Organization (WHO). This air pollution contributes to 4.2 million premature deaths worldwide due to heart disease, lung cancer, and acute respiratory infections in children. Many organizations have sought to enact health and safety laws and standards to protect workers from workplace airborne exposures, including the Occupational Safety and Health Administration (OSHA). According to OSHA, more than five million U.S. workers must wear respirators at more than 1.3 million workplaces across the country.

Many types of respirators are used to protect workers' respiratory systems, including negative pressure half and full facepiece respirators, powered air-purifying respirators (PAPR), and supplied air respirators such as self-contained breathing apparatus (SCBA). Previous studies have determined the efficiency of respirators, particularly surgical masks, N95 respirators, and PAPRs against submicron particulate aerosols. Some studies have linked acceptance and use of respirators with user comfort. Many users feel uncomfortable while wearing respirators. Studies have shown that a combination of factors contribute to this discomfort including eye and thermal discomfort, headaches, and interference with duties.

Because respirators may cause wearer discomfort and because humans breathe $90 \%$ of their air through their nose at rest and minimal work, innovative nasal filters have been designed to enhance the filtering of air entering through the nose. Typically, nasal filters are used in situations such as farmers against pollen allergy and casino workers against secondhand smoke. However, few studies have measured the actual efficiency of nasal filters when used in these situations. Many nasal filter manufacturers claim their devices are efficient against air pollution, but again studies have not been done to evaluate these claims. The current study is designed to evaluate the 
efficiency of five models of nasal filters against tobacco smoke and sodium chloride particle matter less than 1 micrometer $(\mu \mathrm{m})$ aerodynamic mass median diameter $\left(\mathrm{PM}_{1}\right)$.

\section{Hypothesis}

1. Under different test airflows (constant and cyclic), there will be a difference in the efficiency of nasal filters against ETS and $\mathrm{PM}_{1}$ particles.

2. Concentration levels and flow rates will be important in explaining the differences in efficiency of ETS and $\mathrm{PM}_{1}$ aerosols between models of nasal filters.

3. In the evaluation, the best nasal filter will be the one that the user finds comfortable to wear and has good efficiency.

\section{Objective}

This study is designed to evaluate the performance of five different models of nasal filters against environmental tobacco smoke (ETS) and $\mathrm{PM}_{1}$ aerosol and to evaluate users' experiences based on perceived comfort of the nasal filters.

\section{Specific Aims}

- Aim 1 (Study I): Evaluate the performance of five models of nasal filters challenged against environmental tobacco smoke (ETS) particulate at different concentrations and flow rates.

- Aim 2 (Study II): Evaluate the performance of five models of nasal filters challenged against $\mathrm{PM}_{1}$ size $\mathrm{NaCl}$ particulate aerosol at different concentrations and flow rates.

- Aim 3 (Study III): Evaluate users' experiences of comfort, suitability, exertion, and total assessment of different types of nasal filters when performing various tasks. 


\section{Table of Contents}

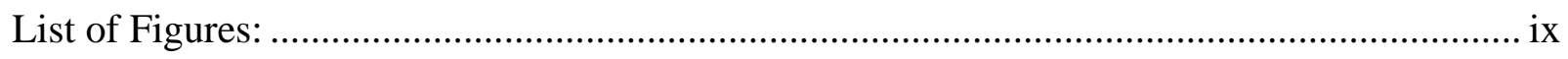

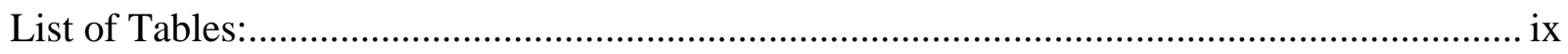

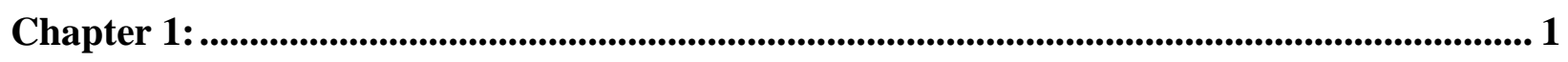

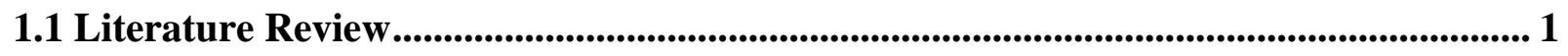

1.1.1 Indoor and Outdoor Air Pollution........................................................................ 1

1.1.2 Health Effects of Air Pollution ............................................................................. 2

1.1.3 Indoor Exposure to Environmental Tobacco Smoke (ETS) ........................................ 3

1.1.4 Health Effects of ETS Exposure ............................................................................... 4

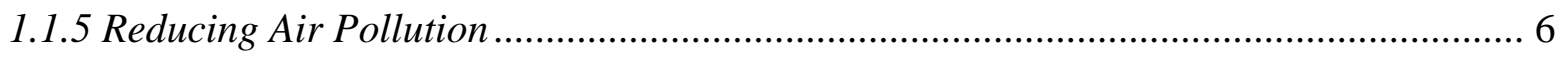

1.1.6 Respirators vs. Nasal Filters ............................................................................. 7

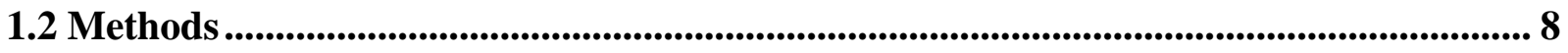

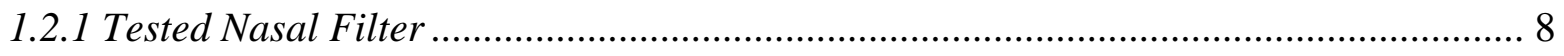

1.2.2 Environmental Tobacco Smoke (ETS)................................................................... 9

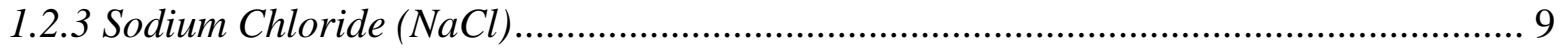

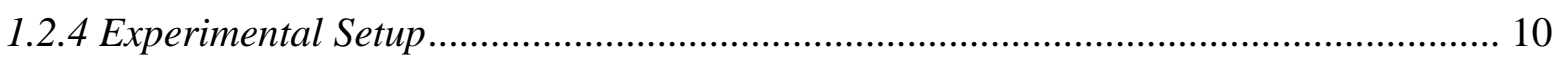

1.3 Data Analysis ........................................................................................................... 11

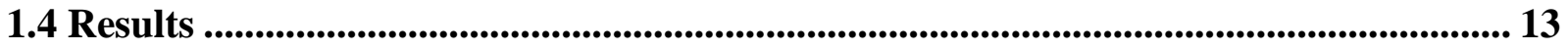

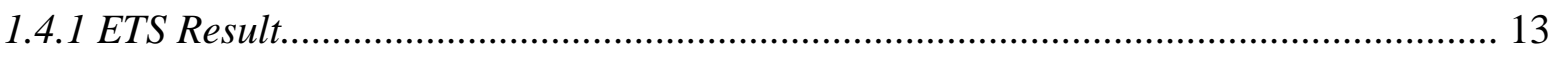

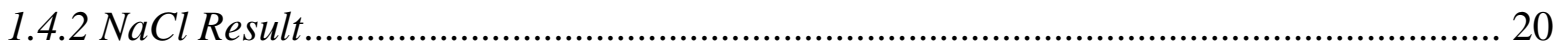

1.4.3 Efficiency distribution of challenge ETS and $\mathrm{NaCl}$................................................ 26

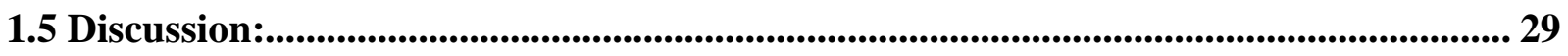

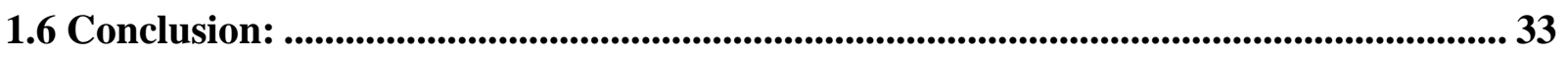

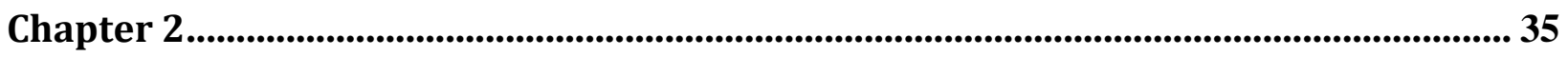

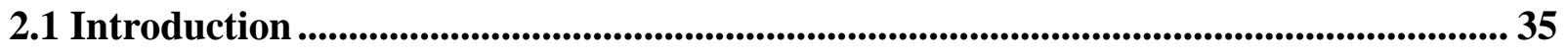

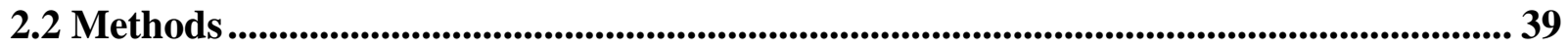

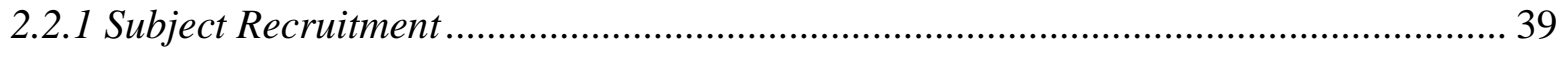

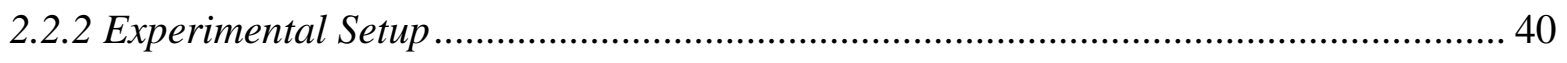

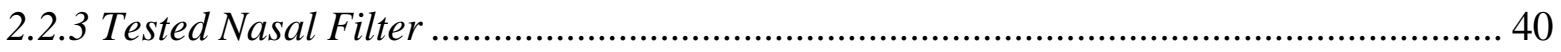

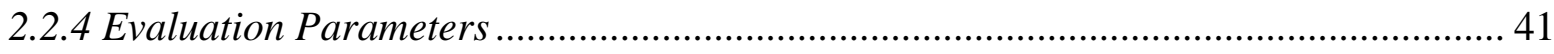

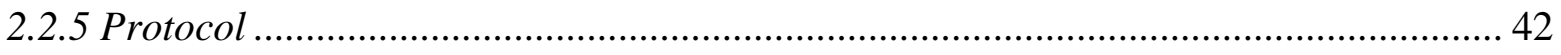


2.3 Data Analysis ..................................................................................................................... 43

2.4 Result and discussion: .................................................................................................................... 43

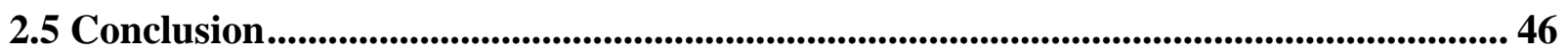

References: ................................................................................................................................ 48

Appendix A: Probability Plots, Normality Check ……............................................................... 62

Appendix B: Johnson Transformation ................................................................................................. 64

\section{List of Figures:}

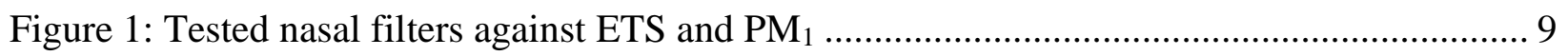

Figure 2: Diagram of ETS experiment set-up (modified from He et al., 2013) .......................... 12

Figure 3: $\mathrm{PM}_{1}$ experiment set-up diagram (modified from He et al., 2013) ................................ 13

Figure 4: Particle size distribution of challenge ETS under constant flow with four different flow

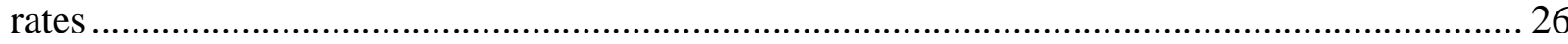

Figure 5: Particle size distribution of challenge ETS under cyclic flow with four different flow

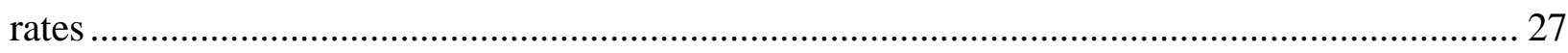

Figure 6: Particle size distribution of challenge $\mathrm{NaCl}$ under constant flow with four different

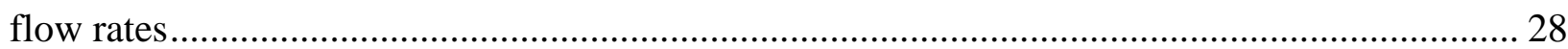

Figure 7: Particle size distribution of challenge $\mathrm{NaCl}$ under cyclic flow with four different flow

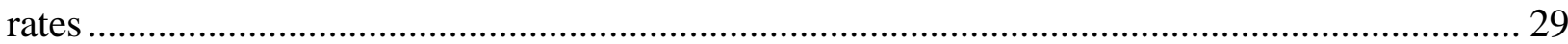

Figure 8: The appropriate nose filter size for the nostril ......................................................... 41

\section{List of Tables:}

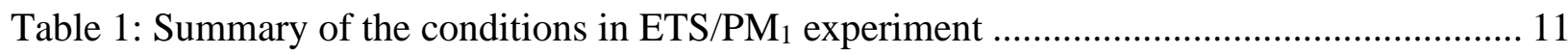

Table 2: Mean ETS Efficiency \% for nasal filters under constant flow and different tested air flows

Table 3: Mean ETS Efficiency \% for nasal filters under cyclic flow and different tested air flows

Table 4: Three-way ANOVA results for the efficiency of nasal filters against ETS under constant flow 
Table 5: Three-way ANOVA results for the efficiency of nasal filters against ETS under cyclic flow

Table 6: Pairwise multiple comparisons: mean ETS efficiency among nasal filters and flow rate under constant air flow.

Table 7: Pairwise multiple comparisons: mean ETS efficiency among nasal filters and flow rate under cyclic air flow

Table 8: Pairwise multiple comparison for the interaction between the nasal filter and flow rate under constant flow

Table 9: Pairwise multiple comparison for the interaction between the nasal filter and flow rate under cyclic flow.

Table 10: Mean $\mathrm{NaCl}$ Efficiency \% for nasal filters under constant flow and different tested air flows.

Table 11: Mean $\mathrm{NaCl}$ Efficiency \% for nasal filters under cyclic flow and different tested air flows

Table 12: Three-way ANOVA results for the efficiency of nasal filters under constant flow in $\mathrm{NaCl}$ study

Table 13: Three-way ANOVA results for the efficiency of nasal filters against $\mathrm{NaCl}$ under cyclic flow

Table 14: Pairwise multiple comparisons: mean $\mathrm{NaCl}$ efficiency among nasal filters and flow rate under constant air flow.

Table 15: Pairwise multiple comparisons: mean $\mathrm{NaCl}$ efficiency among nasal filters and flow rate under cyclic air flow

Table 16: Pairwise multiple comparison for the interaction between the nasal filter and

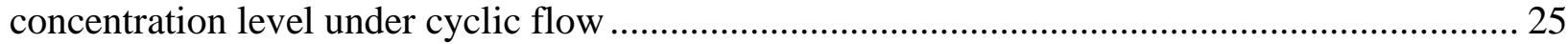

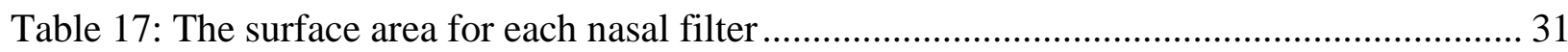

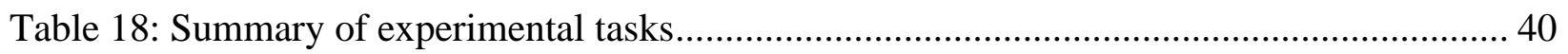

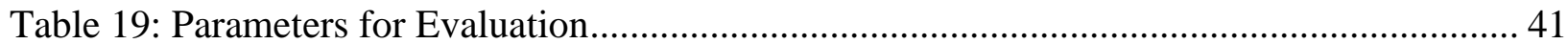

Table 20: Evaluation statistical results for all nasal filters ........................................................ 43

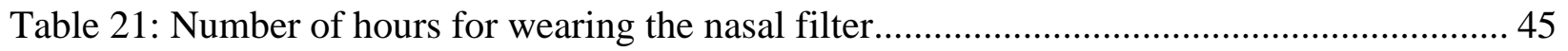

Table 22: Kruskal-Wallis test results when comparing between the nasal filters ......................... 46 


\section{Chapter 1:}

\section{Study of five models of nasal filters against environmental tobacco smoke (ETS) and PM1 with different levels of concentration and flow rate.}

\subsection{Literature Review}

\subsubsection{Indoor and Outdoor Air Pollution}

Currently, people spend nearly two-thirds of their time indoors, such as in homes, gyms, workplaces, and cars (Le Cann et al., 2011). Sometimes indoor air can be more hazardous than outdoor air, and if the exposure to air pollutants (e.g., tobacco smoking, cleaning supplies, paints, carpet, etc.) increases, it may cause physical, psychological, and respiratory health problems. The concentration levels of indoor air pollutants can be two to five times higher than outdoor concentration levels, and in some case these levels can exceed 100 times EPA regulations (EPA, 1995). Health care costs from exposure to indoor air pollution are around $\$ 10$ billion in the United States (Mendell et al., 2002). In China, the economic losses caused directly and indirectly by indoor air pollution have amounted to nearly $\$ 10.7$ billion (Xie, 2018).

Indoor air quality (IAQ) has a direct impact on human health and quality of life. Customarily, outdoor air is transmitted through infiltration or natural or mechanical ventilation systems to mix with indoor air. Indoor air contains a mixture of both outdoor pollutants (e.g., vehicle exhaust, industrial waste) and indoor contaminants (e.g., combustion products, building materials, and household cleaning solvents). For this reason, indoor air pollution poses a greater risk to human health than outdoor air pollution. Thus, the concentration level of indoor air pollution is higher than that in outdoor air pollution. The primary indoor air pollutants which have been 
measured and linked to human health include particulate matter (PM), volatile organic compounds (VOCs), carbon dioxide $\left(\mathrm{CO}_{2}\right)$, heavy metals, and several biological agents.

Outdoor air pollution is a global threat from factors such as the coal industry, transportation, anthropogenic dust, and fossil energy consumption. Numerous studies have shown how air pollution harms human health, including respiratory diseases, heart problems, lung cancer, and skin aging. Worldwide, outdoor air pollution caused 4.2 million premature deaths in 2016 , and nearly $40 \%$ of deaths due to outdoor air pollution were in China (Lim et al., 2012). According to a World Bank report, deaths from air pollution cost the world economy the US equivalent of \$225 billion in lost labor income in 2013. Numerous epidemiological studies have suggested a close correlation between urban mortality and atmospheric particulate concentration.

\subsubsection{Health Effects of Air Pollution}

Various medical and epidemiological studies have reported on the association between exposure to indoor and outdoor air pollution and health problems. Indoor air pollution has been linked with the development of many diseases and injuries to respiratory and cardiovascular systems in the human body. Several studies have also found that exposure to biomass smoke increases the incidence of respiratory infections and tuberculosis in children (Collings et al., 1990; Dherani et al., 2008; Robin et al., 1996). Moreover, numerous studies have claimed that exposure to indoor air pollution can cause lung cancer in adults (Pérez, et al., 2010; Sapkota, et al., 2008). Infants in developing countries are at greater risk for having low birth weight (LBW) as a result of indoor air pollution (Boy, et al., 2002; Pope, et al., 2010; WHO, 2007). Samet et al., found enough evidence to causally link inhaled indoor pollutants to cardiovascular disease.

Governments have cooperated with international organizations and scientists to fund research that addresses the risks of air pollution threatening human health. Numerous 
epidemiological studies have suggested a close correlation between urban mortality and atmospheric particulate concentration and particle size. The smaller the particle sizes in the atmosphere, the greater the incidence of lung cancer, heart disease, and mortality (Pope III et al., 2002; Losonczy G, 2012; Hu et al., 2018). The size of the particles is divided into several groups according to aerodynamic diameter; $\mathrm{PM}_{10}$ "Coarse particles" are between 2.5-10 $\mu \mathrm{m}$; $\mathrm{PM}_{2.5}$ "Fine particles" are between 0.1- 2.5 $\mu \mathrm{m}$, and UFPs "Ultrafine particles" are less than $0.1 \mu \mathrm{m}$ (Polichetti et al., 2009). $\mathrm{PM}_{1}$ is particulate matter with an aerodynamic diameter of $<1 \mu \mathrm{m}$. $\mathrm{PM}_{1}$ is also a major part of $\mathrm{PM}_{2.5}$ and is more strongly linked to heart disease than $\mathrm{PM}_{2.5}$ (Yang et al., 2019). Moreover, $\mathrm{PM}_{1}$ has a larger surface area than $\mathrm{PM}_{2.5}$ and therefore can carry more toxic pollutants, such as heavy metals, bacteria, and virus. $\mathrm{PM}_{1}$ can penetrate deeper into the human lung (Patterson et al., 2014; Gaita et al., 2016).

\subsubsection{Indoor Exposure to Environmental Tobacco Smoke (ETS)}

Environmental tobacco smoke (ETS) refers to exposure to "secondhand smoke". This exposure occurs when a bystander inhales the smoke released when someone is smoking a cigarette, pipe, or cigar. ETS contains a complex mixture of approximately 5,000 chemicals, which include about fifty carcinogens (Repace, 1993). Tobacco cigarette smoke is mainly comprised of ultrafine particles $\mathrm{PM}_{1}(84 \%-91 \%)$ and fine particles $\mathrm{PM}_{2.5}(8.6 \%-15.5 \%)$ (Kant et al.,2016). Exposure to ETS among children, adolescents, and adults is associated with an increased risk of allergic rhinitis and eczema (Singh et al., 2016), increased risk of respiratory tract infection (Bielska et al., 2015), increased risk of asthma, infection, cancer, cardiovascular effects, and sleep difficulties (Treyster and Gitterman, 2011), and increased risk of hearing loss (Talaat et al., 2014). Forty percent of the world's children are exposed to ETS. As a result, ETS annually accounts for nine hundred deaths among infants (Max et al., 2012; Oberg et al., 2011). Annually, secondhand 
smoke causes 7,333 deaths from lung cancer and 33,951 deaths from cardiovascular disease in the United States (HHS, 2014). In the United States, the annual lost productivity cost attributed to ETS exposure was $\$ 6.6$ billion (Max et al., 2012).

Throughout the world, casinos are often exempted from smoke-free laws, which expose occupants to fine particles $\left(\mathrm{PM}_{2.5}\right)$ from secondhand smoke (SHS). Casinos are one of the most entertaining places for adults. In 2016, 26\% of American adults (approximately 64 million) went to casinos at least once a year (Matt et al., 2018). Annually, there are more than fifty million nonsmoking casino patrons and 400,000 non-smoking casino workers (Myers, 2011). In 2014, California received $\$ 7$ billion in annual revenue from over 70,000 slot machines in 69 tribal-owned casinos that allowed indoor smoking (Klepeis et al., 2016; Meister, 2005). High concentrations of SHS are typically found in permitted indoor smoking areas (e.g., bars, restaurants, private homes, cars). Because smoking is allowed 24 hours every day of the year, casinos contain some of the most dangerous and contaminated indoor air. Consistent high levels of SHS in the indoor air leads to the accumulation of residual nicotine and other chemicals on indoor surfaces. This accumulation of residual nicotine and other chemicals is called third-hand smoke (THS). Several studies have shown that THS is cytotoxic and encompasses a variety of carcinogens and irritants (Bahl et al., 2016; Sleiman et al., 2014).

\subsubsection{Health Effects of ETS Exposure}

One of the most important methods used to measure indoor air quality is the measurement of particulate matter (PM). Several studies of indoor air pollution in casinos have used $\mathrm{PM}_{2.5}$ measurement devices. In 66 casinos throughout the United States, air pollution levels for $\mathrm{PM}_{2.5}$ exceeded WHO standards in more than $90 \%$ of cases (Repace et al., 2011). Many studies have found that exposure to SHS in casinos for 1-2 hours caused patrons and workers to develop a low 
heart rate which impairs the heart's ability to pump blood and increases the risk of cardiovascular disease (Pope et al., 2001; Repace et al., 2011). A survey of 559 workers exposed to SHS in London casinos revealed that $91 \%$ of them reported symptoms of irritability over the past four weeks, and $84 \%$ of them reported respiratory symptoms (Pilkington et al., 2007). Another study utilized exposure-response models and air quality standards to assess the impact of SHS on workers and patrons in Pennsylvania casinos. The study found that lung cancer caused by exposure to SHS brought about six deaths per 10,000 annually (Repace, 2009).

Matt et al. examined SHS and THS pollution in order to measure the concentration level of $\mathrm{PM}_{2.5}$ and nicotine before, during, and after a casino smoking ban was implemented. The authors visited the same casino nine times over a fifteen-month period to obtain air samples and collect urine samples from non-smoking employees. These urine samples were obtained at the beginning and the end of each four-hour casino visit. Results showed that long-term smoking creates deep THS reservoirs that persisted for months after the prohibition was put in place. Furthermore, the study also demonstrated that a total smoking ban improves air quality and reduces exposure to SHS and THS. Another study showed that exposure to SHS leads to increased levels of tobaccospecific biomarkers in blood, urine, and saliva of non-smoking workers and visitors (Babb et al., 2015). In addition, casino workers exposed to SHS have an increased risk of developing DNA damage, which can lead to lung cancer and heart disease (Collier et al., 2005). The 2006 U.S. Surgeon General reported that the most effective way to eliminate SHS exposure was to implement a total smoking ban in all indoor casinos. Ventilation and air filtration systems may reduce exposure to SHS, but they cannot eliminate SHS exposure. Smoke can spread throughout a building through heating, ventilation, and air-conditioning systems. To prevent tobacco smoke 
from entering inside the casino, NIOSH recommended a smoking ban near building entrances (Achutan et al., 2009).

\subsubsection{Reducing Air Pollution}

By virtue of government regulations and standards, air quality improved significantly after the mid-1990s. This contributed to 780 fewer deaths and 2,000 fewer emergency room visits in New York City during 2009-2011 (PlaNYC, 2014); 660 fewer premature deaths, and 1,090 fewer emergency room visits in Ontario during 2000-2005 (Boulton et al., 2005); and 57\% fewer deaths due to coal consumption in Beijing in 2017 (Spegele, 2015). The major source of ambient air pollution in big cities is vehicle emissions from fossil fuel. To remedy this danger, many countries have imposed laws on road transportation in urban areas. More than ten European countries including England, Italy, Sweden, and the Netherlands have adopted "low emission zones (LEZ)" laws to reduce exhaust pollution from heavy-duty vehicles, diesel vehicles, and older vehicles (Holman et al., 2015; Bigazzi and Rouleau, 2017). Several countries use technology to reduce pollutants from the air. For instance, China has built an air-purifying tower (100 m) in Xi'an to clean polluted air through a filtration system (Lewis, 2018). India has used water cannons to wash pollution out of the air in Delhi, which has had a positive impact on air quality (Suri, 2017).

Despite positive reforms by governments, air pollution in $91 \%$ of urban cities worldwide is still above WHO air quality guideline levels $\left(\mathrm{PM}_{2.5} 10 \mu \mathrm{g} / \mathrm{m} 3\right)(\mathrm{WHO}, 2016)$. The concept of respiratory protection extends beyond the health care community to individuals worldwide, so that even people who work outdoor/indoor, such as casino workers, traffic police, pavement cleaners, and construction road workers can choose effective respiratory protective equipment. 


\subsubsection{Respirators vs. Nasal Filters}

In todays' workplace, filtering facepiece respirators (FFR) are frequently used by indoor/outdoor workers to reduce exposure to airborne particulate pollution (Chen et al., 2016; Adhikari et al., 2018). An air-purifying respirator such as the N95 FFR or the P100 FFR collects 95-99.9\% of the most penetrating size aerosol, so wearing them in indoor/outdoor working areas can minimize exposure to air pollution. OSHA has enacted several standards to address respiratory protection in general industry (29 CFR 1910.134), shipyards (29 CFR 1915.154), marine terminals (29 CFR 1917.92), longshoring (29 CFR 1918.102), and construction (29 CFR 1926.103). Some workers using negative pressure respirators experience trouble with breathing, and unintelligible speech (Johnson, 2016; Rebmann et al., 2013; Zhu et al., 2014). Many studies have also reported that workers experience discomfort while wearing FFRs (Davidson et al., 2013; Locatelli, et al., 2014). FFRs may cause skin irritation (Harber et al., 2010; Radonovich et al., 2008; Liverman \& Goldfrank, 2007).

Most of the air entering the respiratory system (80-90\%) in adults at rest condition is inhaled through the nose (Kleinman, 1984). Breathing through the nose reduces the risk of a cold, enhances stamina, and promotes cardiovascular health (Lundberg 2008; Noback et al., 2011; Travis et al., 1996).

Recently, manufactures have developed innovative nasal filters, which are designed to increase the effectiveness of nasal filtration by inserting small filters into each nostril. Nasal filters are not readily visible, easy to put in the nose, and allow for clearer communication because they do not cover the wearer's mouth. However, the effectiveness of such devices to reduce exposures has not been demonstrated and may be substantially less than NIOSH certified respirators. Researchers have reported that in a small percentage of user's nasal filters may cause nasal 
discomfort while breathing (Pasricha, 1981). Also, nasal filters only protect against aerosol breathed through the nose, therefore they are only suitable for use at rest or at a minimal work rate. Because of the breathing resistance they cause through the nose they may cause more mouth breathing.

Few studies have been published concerning the effectiveness of nasal filters to protect the respiratory system. Kenney et al. (2015) found that nasal filters were effective in preventing seasonal allergic rhinitis (SAR). Furthermore, O'Meara et al. (2005) found that wearing nasal filters significantly reduced the incidences of sneezes, runny nose, itchy nose, sniffles, itchy throat, and itchy eyes during natural exposure to ragweed and grass pollen. Despite the few studies showing the positive effect of nasal filters on the respiratory system on allergic rhinitis and when exposed to grass pollen, there has been no study yet demonstrating the effectiveness of nasal filters against ETS and $\mathrm{PM}_{1}$. By using a new nasal filter test system, we were able to evaluate the performance and efficiency of different models of nasal filters against ETS and PM${ }_{1}$.

\subsection{Methods}

\subsubsection{Tested Nasal Filter}

The five different models of nasal filters selected for study were all designed to protect against air pollution. These nasal filters consisted of two flexible double-filter frames connected by a clear connector. A retainer ring secures the filter inside the frame. The filter material is manufactured from an electrostatic nanofiber. The frames are soft and ergonomically designed to allow the nasal filters to be easily inserted into the nostrils. The connector between the two frames has several advantages. It prevents the filter from being inserted too far into the nasal vestibule and it eases the removal of the nasal filters. After insertion, the connector is located under the nose and its clear color makes it almost invisible to the outside observer. Two of the five nasal filter 
models come in three sizes (small, medium, large). The five models of nasal filters are shown in Figure 1.

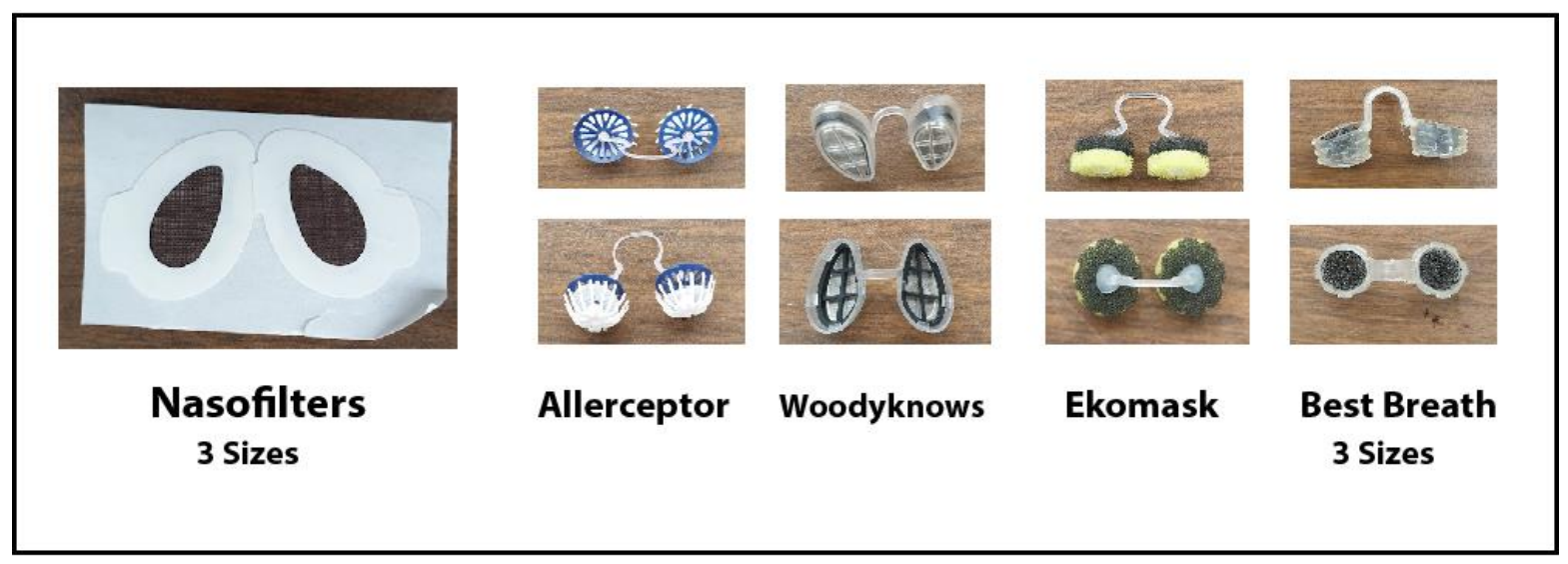

Figure 1: Tested nasal filters against ETS and PM $_{1}$

\subsubsection{Environmental Tobacco Smoke (ETS)}

ETS was produced from Camel Blue regular cigarettes. A lite cigarette was placed inside a test chamber $\left(1.2 \times 1.2 \times 1.2 \mathrm{~m}^{3}\right)$ (Figure 2$)$. Four fans placed at each corner of the test chamber were used to mix the smoke and brought it to a stable concentration level. For each test, the concentration measurements reached the desired concentration level $(400,000 ; 200,000 ; 100,000$ particles $/ \mathrm{cm}^{3}$ ) after the cigarette had been extinguished for 5, 9, and 11 minutes, respectively.

\subsubsection{Sodium Chloride ( $\mathrm{NaCl})$}

Sodium chloride $(\mathrm{NaCl})$ particles $(0.02-1 \mu \mathrm{m})$ were produced by using a particle generator (Model 8026, TSI Inc., Shoreview, Minn.) that aerosolizes a liquid salt solution into the test chamber to produce the $\mathrm{PM}_{1}$ challenge aerosol (Figure 3). Concentration levels of 100,000, 200,000, and 400,000 particles/ $\mathrm{cm}^{3}$ were used to test each model nasal filter. The particle concentration in the chamber was allowed to equilibrate for 45-60 minutes before testing began. The generator was operated continually during chamber testing. 


\subsubsection{Experimental Setup}

The efficiency of nasal filters was evaluated by measuring the ETS and $\mathrm{NaCl}$ aerosol penetration through the filter. NIOSH-approved particulate respirators are tested under constant flow conditions at $85 \mathrm{~L} / \mathrm{min}$ (NIOSH, 1995). However, the human breathing pattern is closer to a sinusoidal, cyclic flow (Cooper, 1960) and many studies have shown that with cyclic flow the penetration of aerosols through $\mathrm{N} 95$ and P100 respirators was higher than with constant flow under 85 L/min flow rate (Eshbaugh et al., 2008; Wang et al., 2012). Other studies have found penetration to be higher with a constant flow rate of $30 \mathrm{~L} / \mathrm{min}$ than with a cyclic flow rate of 30 L/min (He et al., 2013). Both flow conditions were evaluated in this study to determine if they have different effects on nasal filter efficiency.

As shown in Figure 2 and 3, to measure and test the efficiency of a nasal filter, the system was designed to approximate the human respiratory system. To simulate the nostrils, two thin walled copper tubes were welded together and connected to a larger, single copper tube that simulated the human's upper respiratory tract. The larger, single copper tube was then connected to either a vacuum pump to produce the constant flow condition or to a breathing simulator (Series 1101, Hans Rudolph, Inc., Shawnee, KS, USA) to produce the cyclic flow condition. For testing, the nasal filters were inserted into the two thin walled copper tubes representing the nostrils. The space between the nasal filter frames and the thin walled tubes was sealed with silicon sealant to prevent leakage around the nasal filter frame. The silicon was allowed to cure for at least thirty minutes before the experiment was carried out. A Nanoscan nanoparticle size counter (Model 3910, TSI Inc., USA) was used to measure particle concentration and size (10 to $420 \mathrm{~nm}$ ) downstream of the nasal filters $\left(\mathrm{C}_{\mathrm{in}}\right)$ and upstream of the nasal filters $\left(\mathrm{C}_{\mathrm{out}}\right)$. The experiments were conducted at West Virginia University using a test chamber $\left(1.2 \times 1.2 \times 1.2 \mathrm{~m}^{3}\right)$. The temperature 
inside the chamber was maintained at $19-23{ }^{\circ} \mathrm{C}$. For each nasal filter, there were two flow conditions, four flow rates, three concentration levels, and three randomized replicates resulting in seventy-two tests for each filter (Table 1). Aerosol penetration (P) through the nasal filter was determined as the ratio of $\mathrm{C}_{\text {in }}$ to $\mathrm{C}_{\text {out }}$ and is described in Equation 1. The efficiency of nasal filter is calculated by subtracting nasal filter penetration from one, as shown in Equation 2.

$$
\begin{gathered}
P=\frac{C_{\text {in }}}{C_{\text {out }}} \\
\text { Efficiency } \%=(1-P) \times 100
\end{gathered}
$$

Table 1: Summary of the conditions in ETS/PM 1 experiment

\begin{tabular}{c|c}
\hline Variable & Levels \\
\hline Nasal Filter & 5 nasal filter \\
Flow Type & Constant flow and Cyclic flow \\
Flow Rate & $15,30,50$, and $85 \mathrm{~L} / \mathrm{min}$ \\
$\begin{array}{c}\text { Concentration } \\
\text { Level }\end{array}$ & $100,000-200,000-400,000$ particles $/ \mathrm{cm}^{3}$ \\
\hline Replicates & 3 \\
\hline $\begin{array}{c}\text { Total Runs per } \\
\text { nasal filter }\end{array}$ & 2 flow types $\times 4$ flow rates $\times 3$ Concentration $\times 3$ replicates $=72$ \\
\hline
\end{tabular}

\subsection{Data Analysis}

Statistical analysis was done using JMP version 14 (SAS Institute Inc., Cary, NC). The mean and standard deviation of ETS and $\mathrm{PM}_{1}$ efficiency were calculated for the three replicates. Analysis of variance (ANOVA) was used to test for differences between nasal filter model, flow type, flow rate, and concentration level on ETS and PM 1 efficiency (Appendix A). Two-way variable interactions were also evaluated. A P-value of $<0.05$ was considered to show significant 
differences in describing our results. With constant flow the ETS and $\mathrm{PM}_{1}$ penetration data was not normally distributed, so the Johnson distribution system was applied to normalize the data. The analysis in Johnson Transformation used to check the normality of original data (ETS and $\mathrm{PM}_{1}$ under constant flow), transform the original data to be normally distributed., and then verify that the transformed data is effective and follow a normal distribution. The transformed data is stored in a new column in the same worksheet for additional analysis (Appendix B). Minitab software version 17 (Minitab Inc., State College, PA) was used for the Johnson transformation method.

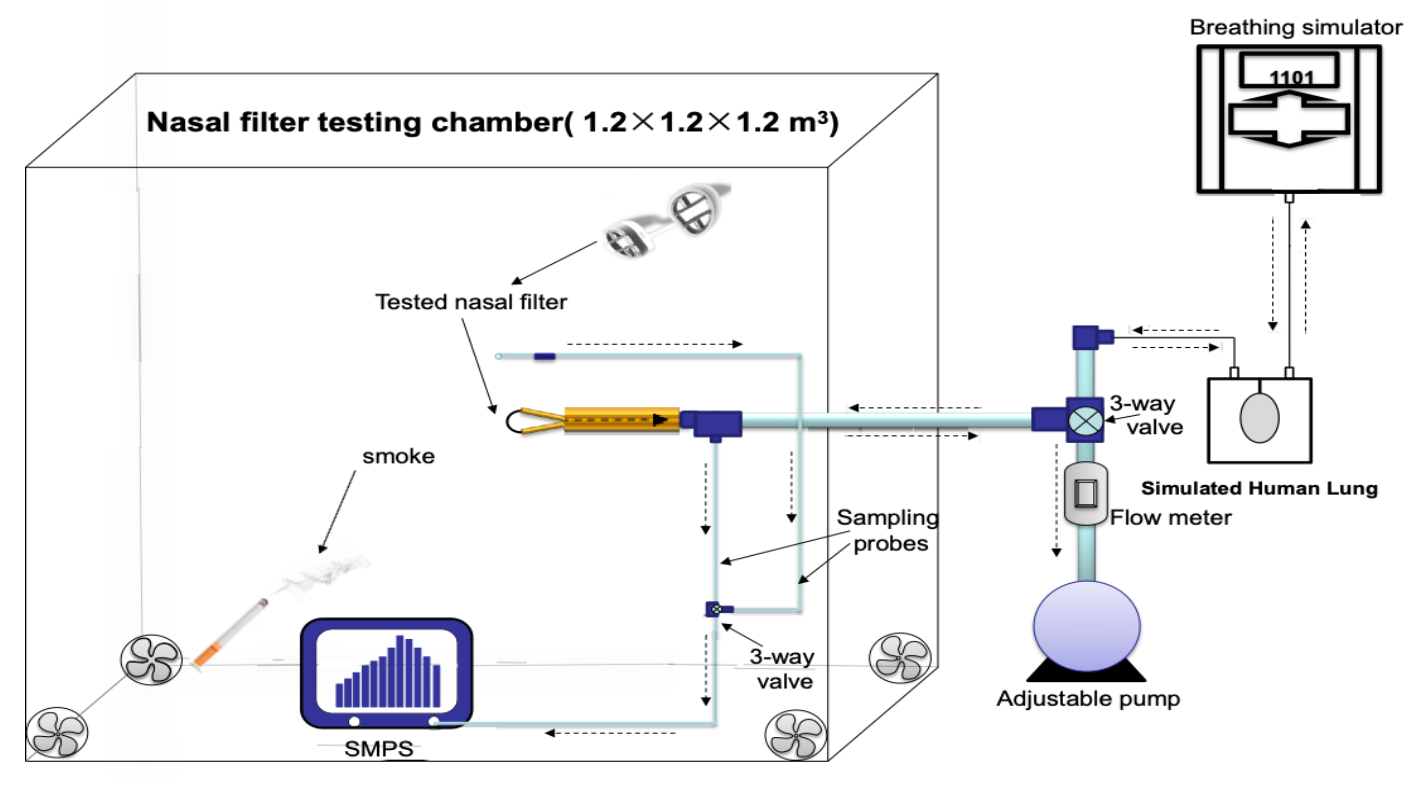

Figure 2: Diagram of ETS experiment set-up (modified from He et al., 2013) 


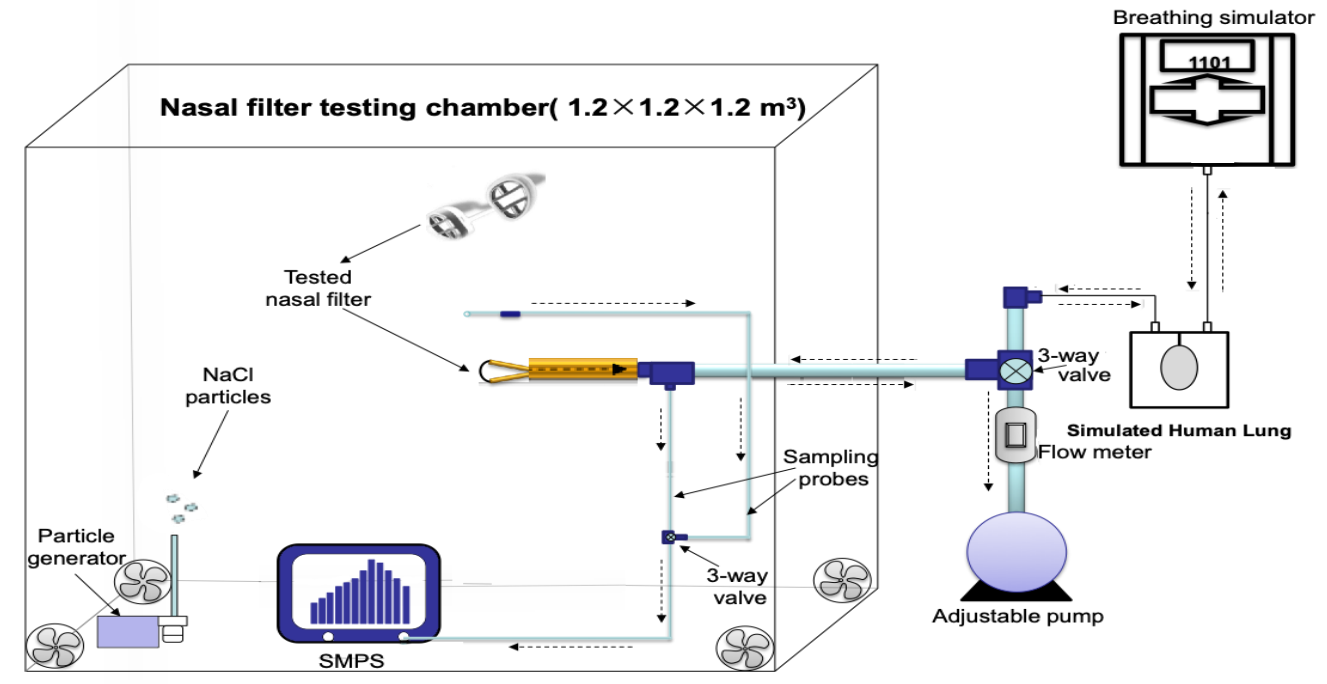

Figure 3: $\mathrm{PM}_{1}$ experiment set-up diagram (modified from He et al., 2013)

\subsection{Results}

\subsubsection{ETS Result}

The mean efficiencies measured under different flow conditions and different flow rates for all models of nasal filters (Woody Knows, Allerceptor, Eko Mask, Best Breath L, Best Breath M, Best Breath S, Naso Filter L, Naso Filter M, and Naso Filter S) are presented in Table 2 and 3. As shown in Table 2, all mean efficiencies were relatively low ranging from 21.16 to $33.32 \%$ under constant flow conditions of 15, 30, 50, and $85 \mathrm{~L} / \mathrm{min}$. Best Breath $\mathrm{S}$ filter had the largest mean efficiency, $33.32 \%$ at $85 \mathrm{~L} / \mathrm{min}$ and Naso Filter $\mathrm{S}$ had the smallest mean efficiency $(21.16 \%)$ at $15 \mathrm{~L} / \mathrm{min}$ flow rate. As seen in Table 3, the mean efficiency values ranged from 47.87 to $65.36 \%$ under cyclic flow conditions of 15, 30, 50, and $85 \mathrm{~L} / \mathrm{min}$. Under cyclic flow, Naso Filter M had the highest efficiency, $65.36 \%$ at $85 \mathrm{~L} / \mathrm{min}$ and Allerceptor had the lowest efficiency, $47.87 \%$ with $50 \mathrm{~L} / \mathrm{min}$ flow rate. 
Table 2: Mean ETS Efficiency \% for nasal filters under constant flow and different tested air flows

\begin{tabular}{|c|c|c|c|c|}
\hline $\begin{array}{l}\text { Nasal Filter } \\
\text { Type }\end{array}$ & $\begin{array}{c}\text { Flow Type } \\
\text { and Flow } \\
\text { Rate (L/min) }\end{array}$ & $\begin{array}{l}\text { Mean Efficiency, \% } \\
(\text { Mean } \pm \text { SD })^{*}\end{array}$ & $\begin{array}{c}\text { Flow Type } \\
\text { and Flow } \\
\text { Rate }(\mathrm{L} / \mathrm{min})\end{array}$ & $\begin{array}{c}\text { Mean Efficiency, \% } \\
\quad(\text { Mean } \pm \text { SD })\end{array}$ \\
\hline \multirow{2}{*}{ Allerceptor } & Constant 15 & $25.68 \pm 1.98$ & Constant 50 & $23.76 \pm 2.59$ \\
\hline & Constant 30 & $26.04 \pm 2.19$ & Constant 85 & $26.15 \pm 1.63$ \\
\hline \multirow{2}{*}{$\begin{array}{l}\text { Best Breath } \\
\text { L }\end{array}$} & Constant 15 & $22.96 \pm 1.04$ & Constant 50 & $25.95 \pm 2.98$ \\
\hline & Constant 30 & $23.83 \pm 2.14$ & Constant 85 & $28.63 \pm 2.00$ \\
\hline \multirow{2}{*}{$\begin{array}{c}\text { Best Breath } \\
\text { M }\end{array}$} & Constant 15 & $23.97 \pm 0.63$ & Constant 50 & $26.18 \pm 0.84$ \\
\hline & Constant 30 & $26.14 \pm 0.87$ & Constant 85 & $28.98 \pm 1.31$ \\
\hline \multirow{2}{*}{$\begin{array}{c}\text { Best Breath } \\
\text { S }\end{array}$} & Constant 15 & $24.80 \pm 1.08$ & Constant 50 & $28.53 \pm 0.54$ \\
\hline & Constant 30 & $25.58 \pm 1.43$ & Constant 85 & $33.32 \pm 0.66$ \\
\hline \multirow{2}{*}{ EKO Mask } & Constant 15 & $21.66 \pm 1.12$ & Constant 50 & $22.28 \pm 1.44$ \\
\hline & Constant 30 & $22.67 \pm 1.34$ & Constant 85 & $25.62 \pm 1.96$ \\
\hline \multirow{2}{*}{$\begin{array}{c}\text { Naso Filter } \\
\text { L }\end{array}$} & Constant 15 & $22.12 \pm 0.99$ & Constant 50 & $24.01 \pm 1.15$ \\
\hline & Constant 30 & $22.67 \pm 0.27$ & Constant 85 & $26.52 \pm 0.57$ \\
\hline \multirow{2}{*}{$\begin{array}{c}\text { Naso Filter } \\
\text { M }\end{array}$} & Constant 15 & $25.64 \pm 2.92$ & Constant 50 & $25.89 \pm 0.77$ \\
\hline & Constant 30 & $26.10 \pm 2.12$ & Constant 85 & $29.98 \pm .81$ \\
\hline \multirow{2}{*}{$\begin{array}{c}\text { Naso Filter } \\
\text { S }\end{array}$} & Constant 15 & $21.16 \pm 1.30$ & Constant 50 & $26.59 \pm 0.49$ \\
\hline & Constant 30 & $22.89 \pm 2.41$ & Constant 85 & $30.68 \pm 2.27$ \\
\hline \multirow{2}{*}{$\begin{array}{l}\text { Woody } \\
\text { Knows }\end{array}$} & Constant 15 & $23.04 \pm 2.00$ & Constant 50 & $26.64 \pm 2.84$ \\
\hline & Constant 30 & $23.67 \pm 1.85$ & Constant 85 & $31.49 \pm 0.96$ \\
\hline
\end{tabular}

Table 3: Mean ETS Efficiency \% for nasal filters under cyclic flow and different tested air flows

\begin{tabular}{ccccc}
\hline $\begin{array}{c}\text { Nasal Filter } \\
\text { Type }\end{array}$ & $\begin{array}{c}\text { Flow Type } \\
\text { and Flow } \\
\text { Rate (L/min) }\end{array}$ & $\begin{array}{c}\text { Mean Efficiency, \% } \\
\text { (Mean } \pm \text { SD) }\end{array}$ & $\begin{array}{c}\text { Flow Type } \\
\text { and Flow } \\
\text { Rate (L/min) }\end{array}$ & $\begin{array}{c}\text { Mean Efficiency, \% } \\
\text { (Mean } \pm \text { SD) }\end{array}$ \\
\hline
\end{tabular}




\begin{tabular}{|c|c|c|c|c|}
\hline \multirow{2}{*}{ Allerceptor } & Cyclic 15 & $58.59 \pm 1.46$ & Cyclic 50 & $47.87 \pm 0.63$ \\
\hline & Cyclic 30 & $58.36 \pm 0.84$ & Cyclic 85 & $56.13 \pm 1.80$ \\
\hline \multirow{2}{*}{$\begin{array}{c}\text { Best Breath } \\
\text { L }\end{array}$} & Cyclic 15 & $60.26 \pm 1.36$ & Cyclic 50 & $57.90 \pm 0.40$ \\
\hline & Cyclic 30 & $62.46 \pm 0.55$ & Cyclic 85 & $53.30 \pm 0.45$ \\
\hline \multirow{2}{*}{$\begin{array}{c}\text { Best Breath } \\
\text { M }\end{array}$} & Cyclic 15 & $58.03 \pm 0.41$ & Cyclic 50 & $57.66 \pm 0.70$ \\
\hline & Cyclic 30 & $55.46 \pm 0.75$ & Cyclic 85 & $59.90 \pm 0.50$ \\
\hline \multirow{2}{*}{$\begin{array}{c}\text { Best Breath } \\
\text { S }\end{array}$} & Cyclic 15 & $52.00 \pm 0.30$ & Cyclic 50 & $57.13 \pm 1.05$ \\
\hline & Cyclic 30 & $52.63 \pm 1.42$ & Cyclic 85 & $54.76 \pm 0.95$ \\
\hline \multirow{2}{*}{ EKO Mask } & Cyclic 15 & $54.44 \pm 0.18$ & Cyclic 50 & $64.48 \pm 1.38$ \\
\hline & Cyclic 30 & $56.49 \pm 0.63$ & Cyclic 85 & $56.29 \pm 0.99$ \\
\hline \multirow{2}{*}{$\begin{array}{c}\text { Naso Filter } \\
\text { L }\end{array}$} & Cyclic 15 & $57.26 \pm 0.25$ & Cyclic 50 & $51.90 \pm 2.10$ \\
\hline & Cyclic 30 & $54.50 \pm 1.80$ & Cyclic 85 & $62.33 \pm 1.32$ \\
\hline \multirow{2}{*}{$\begin{array}{c}\text { Naso Filter } \\
\mathrm{M}\end{array}$} & Cyclic 15 & $55.73 \pm 0.55$ & Cyclic 50 & $65.36 \pm 0.50$ \\
\hline & Cyclic 30 & $55.40 \pm 0.70$ & Cyclic 85 & $57.20 \pm 0.91$ \\
\hline \multirow{2}{*}{$\begin{array}{c}\text { Naso Filter } \\
\text { S }\end{array}$} & Cyclic 15 & $50.26 \pm 1.68$ & Cyclic 50 & $55.56 \pm 1.45$ \\
\hline & Cyclic 30 & $53.16 \pm 4.20$ & Cyclic 85 & $60.63 \pm 0.81$ \\
\hline \multirow{2}{*}{$\begin{array}{l}\text { Woody } \\
\text { Knows }\end{array}$} & Cyclic 15 & $52.18 \pm 1.36$ & Cyclic 50 & $52.37 \pm 1.06$ \\
\hline & Cyclic 30 & $54.50 \pm 0.68$ & Cyclic 85 & $49.65 \pm 0.61$ \\
\hline
\end{tabular}

A three-way ANOVA analysis with interaction found that nasal filter type, concentration, flow rate, and the interaction between nasal filter type and flow rate had a significant effect on nasal filter efficiency $(\mathrm{P}<0.05)$ against ETS for both flow conditions. However, the interaction between nasal filter type and concentration and the interaction between concentration and flow rate were not found to have a significant effect on ETS efficiency ( $\mathrm{P}>0.05$; see Table 4 and 5). 
Table 4: Three-way ANOVA results for the efficiency of nasal filters against ETS under constant flow

\begin{tabular}{lcccc}
\hline Source & DF & Sum of Squares & F Ratio & P value \\
\hline Nasal Filter Type & 8 & 21.96 & 15.84 & $<.0001^{*}$ \\
Concentration & 2 & 9.32 & 26.92 & $<.0001^{*}$ \\
Flow Rate & 3 & 43.63 & 83.95 & $<.0001^{*}$ \\
Nasal Filter Type*Concentration & 16 & 2.88 & 1.03 & 0.4358 \\
Nasal Filter Type*Flow Rate & 24 & 14.67 & 3.53 & $<.0001^{*}$ \\
Concentration*Flow Rate & 6 & 1.58 & 1.52 & 0.1904 \\
\hline
\end{tabular}

Table 5: Three-way ANOVA results for the efficiency of nasal filters against ETS under cyclic flow

\begin{tabular}{lcccc}
\hline \multicolumn{1}{c}{ Source } & DF & Sum of Squares & F Ratio & P value \\
\hline Nasal Filter Type & 8 & 0.046 & 42.16 & $<.0001^{*}$ \\
Concentration & 2 & 0.001 & 3.86 & $0.0277^{*}$ \\
Flow Rate & 3 & 0.003 & 7.75 & $0.0003^{*}$ \\
Nasal Filter Type*Concentration & 16 & 0.002 & 1.20 & 0.3017 \\
Nasal Filter Type*Flow Rate & 24 & 0.117 & 35.66 & $<.0001^{*}$ \\
Concentration*Flow Rate & 6 & 0.0009 & 1.19 & 0.3245 \\
\hline
\end{tabular}

Further analysis was performed using the pairwise multiple comparison method to assess the significance of the efficiency changes when measuring each variable (nasal filter, concentration level, flow rate, and the interaction between the nasal filter and flow rate) at designated levels. The results of the pairwise multiple comparison for all nasal filters, concentration levels, and flow rates are listed in Table 6 for constant flow and Table 7 for cyclic flow. The results of the pairwise multiple comparison for the interaction between the nasal filter and flow rate are listed in Table 8 for constant flow and Table 9 for cyclic flow. There was a significant difference in the mean efficiency values between the types and sizes of nasal filters. For the three levels of concentration, the mean efficiency was the highest at 400,000 particles $/ \mathrm{cm}^{3}$, followed by 200,000 and 100,000 particles $/ \mathrm{cm}^{3}$. The pairwise comparison of ETS efficiency found significant differences between 
flow rates. Also, In the pairwise comparison, the interaction between the nasal filter type and flow rate showed that the mean efficiency that we got from the nasal filters was significantly affected by the different flow rates.

Table 6: Pairwise multiple comparisons: mean ETS efficiency among nasal filters and flow rate under constant air flow

\begin{tabular}{|c|c|c|c|}
\hline Variable & Mean Efficiency\% & Levels & Grouping $\psi$ \\
\hline \multirow{9}{*}{ Filter Type } & 28.06 & Best Breath $\mathrm{S}$ & $\mathrm{A}$ \\
\hline & 26.91 & Naso Filter M & A B \\
\hline & 26.32 & Best Breath M & $\mathrm{B} \mathrm{C}$ \\
\hline & 26.22 & Woody Knows & B C \\
\hline & 25.41 & Allerceptor & C D \\
\hline & 25.35 & Best Breath L & C D \\
\hline & 25.33 & Naso Filter $\mathrm{S}$ & D E \\
\hline & 23.84 & Naso Filter L & E F \\
\hline & 23.06 & Eko Mask & $\mathrm{F}$ \\
\hline \multirow{3}{*}{ Concentration } & 26.71 & 400 & $\mathrm{~A}$ \\
\hline & 25.52 & 200 & B \\
\hline & 24.60 & 100 & $\mathrm{C}$ \\
\hline \multirow{4}{*}{ Flow Rate } & 29.04 & 85 & $\mathrm{~A}$ \\
\hline & 25.54 & 50 & B \\
\hline & 24.40 & 30 & $\mathrm{C}$ \\
\hline & 23.45 & 15 & $\mathrm{D}$ \\
\hline
\end{tabular}

${ }^{\psi}$ Means with different letters are significantly different

Table 7: Pairwise multiple comparisons: mean ETS efficiency among nasal filters and flow rate under cyclic air flow

\begin{tabular}{|c|c|c|c|}
\hline Variable & Mean Efficiency \% & Levels & Grouping $\psi$ \\
\hline \multirow{9}{*}{ Filter Type } & 58.48 & Best Breath L & A \\
\hline & 58.43 & Naso Filter M & A \\
\hline & 57.93 & Eko Mask & A \\
\hline & 57.77 & Best Breath M & A \\
\hline & 56.50 & Naso Filter L & B \\
\hline & 55.24 & Allerceptor & $\mathrm{C}$ \\
\hline & 54.91 & Naso Filter S & C D \\
\hline & 54.13 & Best Breath S & $\mathrm{D}$ \\
\hline & 52.18 & Woody Knows & E \\
\hline \multirow{2}{*}{ Concentration } & 56.55 & 400 & A \\
\hline & 56.19 & 200 & A B \\
\hline
\end{tabular}




\begin{tabular}{lccc} 
& 55.78 & 100 & B \\
\hline \multirow{3}{*}{ Flow Rate } & 56.70 & 50 & $\mathrm{~A}$ \\
& 56.69 & 85 & $\mathrm{~A}$ \\
& 55.89 & 30 & $\mathrm{~B}$ \\
& 55.42 & 15 & $\mathrm{~B}$ \\
\hline
\end{tabular}

${ }^{\psi}$ Means with different letters are significantly different

Table 8: Pairwise multiple comparison for the interaction between the nasal filter and flow rate under constant flow

\begin{tabular}{|c|c|c|c|c|c|c|c|c|c|c|}
\hline Nasal Type*Flow Rate & & & & & & & & & & Mean Efficiency $\%$ \\
\hline Best Breath $\mathrm{S}, 85$ & A & & & & & & & & & 33.32 \\
\hline Woody Knows, 85 & A & $\mathrm{B}$ & & & & & & & & 31.49 \\
\hline Naso Filter $\mathrm{S}, 85$ & A & $\mathrm{B}$ & $\mathrm{C}$ & & & & & & & 30.69 \\
\hline Naso Filter M,85 & A & $\mathrm{B}$ & $\mathrm{C}$ & $\mathrm{D}$ & & & & & & 29.98 \\
\hline Best Breath M,85 & A & $\mathrm{B}$ & $\mathrm{C}$ & $\mathrm{D}$ & $\mathrm{E}$ & & & & & 28.98 \\
\hline Best Breath L,85 & & $\mathrm{B}$ & $\mathrm{C}$ & $\mathrm{D}$ & $\mathrm{E}$ & & & & & 28.63 \\
\hline Best Breath S,50 & & $\mathrm{B}$ & $\mathrm{C}$ & $\mathrm{D}$ & $\mathrm{E}$ & $\mathrm{F}$ & & & & 28.54 \\
\hline Woody Knows,50 & & & $\mathrm{C}$ & $\mathrm{D}$ & $\mathrm{E}$ & $\mathrm{F}$ & $\mathrm{G}$ & & & 26.65 \\
\hline Naso Filter S,50 & & & $\mathrm{C}$ & $\mathrm{D}$ & $\mathrm{E}$ & $\mathrm{F}$ & $\mathrm{G}$ & & & 26.59 \\
\hline Naso Filter L,85 & & & $\mathrm{C}$ & $\mathrm{D}$ & $\mathrm{E}$ & $\mathrm{F}$ & $\mathrm{G}$ & & & 26.52 \\
\hline Best Breath M,50 & & & $\mathrm{C}$ & $\mathrm{D}$ & $\mathrm{E}$ & $\mathrm{F}$ & $\mathrm{G}$ & $\mathrm{H}$ & & 26.18 \\
\hline Allerceptor,85 & & & $\mathrm{C}$ & $\mathrm{D}$ & $\mathrm{E}$ & $\mathrm{F}$ & $\mathrm{G}$ & $\mathrm{H}$ & & 26.15 \\
\hline Best Breath M,30 & & & $\mathrm{C}$ & $\mathrm{D}$ & $\mathrm{E}$ & $\mathrm{F}$ & $\mathrm{G}$ & $\mathrm{H}$ & & 26.15 \\
\hline Naso Filter M,30 & & & $\mathrm{C}$ & $\mathrm{D}$ & $\mathrm{E}$ & $\mathrm{F}$ & $\mathrm{G}$ & $\mathrm{H}$ & & 26.11 \\
\hline Allerceptor,30 & & & & $\mathrm{D}$ & $\mathrm{E}$ & $\mathrm{F}$ & $\mathrm{G}$ & $\mathrm{H}$ & & 26.04 \\
\hline Best Breath L,50 & & & & $\mathrm{D}$ & $\mathrm{E}$ & $\mathrm{F}$ & $\mathrm{G}$ & $\mathrm{H}$ & & 25.96 \\
\hline Naso Filter M,50 & & & & $\mathrm{D}$ & $\mathrm{E}$ & $\mathrm{F}$ & $\mathrm{G}$ & $\mathrm{H}$ & & 25.90 \\
\hline Allerceptor,15 & & & & $\mathrm{D}$ & $\mathrm{E}$ & $\mathrm{F}$ & $\mathrm{G}$ & $\mathrm{H}$ & I & 25.69 \\
\hline Naso Filter M,15 & & & & $\mathrm{D}$ & $\mathrm{E}$ & $\mathrm{F}$ & $\mathrm{G}$ & $\mathrm{H}$ & $\mathrm{I}$ & 25.64 \\
\hline Eko Mask,85 & & & & $\mathrm{D}$ & $\mathrm{E}$ & $\mathrm{F}$ & G & $\mathrm{H}$ & I & 25.63 \\
\hline Best Breath S,30 & & & & $\mathrm{D}$ & $\mathrm{E}$ & $\mathrm{F}$ & $\mathrm{G}$ & $\mathrm{H}$ & $\mathrm{I}$ & 25.58 \\
\hline Best Breath $S, 15$ & & & & & $\mathrm{E}$ & $\mathrm{F}$ & $\mathrm{G}$ & $\mathrm{H}$ & $\mathrm{I}$ & 24.81 \\
\hline Naso Filter L,50 & & & & & & $\mathrm{F}$ & $\mathrm{G}$ & $\mathrm{H}$ & $\mathrm{I}$ & 24.02 \\
\hline Best Breath M,15 & & & & & & $\mathrm{F}$ & $\mathrm{G}$ & $\mathrm{H}$ & $\mathrm{I}$ & 23.97 \\
\hline Best Breath L,30 & & & & & & & $\mathrm{G}$ & $\mathrm{H}$ & $\mathrm{I}$ & 23.83 \\
\hline Allerceptor,50 & & & & & & & $\mathrm{G}$ & $\mathrm{H}$ & I & 23.76 \\
\hline Woody Knows,30 & & & & & & & $\mathrm{G}$ & $\mathrm{H}$ & I & 23.67 \\
\hline Woody Knows, 15 & & & & & & & $\mathrm{G}$ & $\mathrm{H}$ & $\mathrm{I}$ & 23.05 \\
\hline
\end{tabular}


Best Breath L, 15

Naso Filter S,30

Naso Filter L,30

Eko Mask,30

Eko Mask,50

Naso Filter L,15

Eko Mask,15

Naso Filter S, 15

$\begin{array}{cccc}\mathrm{G} & \mathrm{H} & \mathrm{I} & 22.96 \\ \mathrm{G} & \mathrm{H} & \mathrm{I} & 22.89 \\ \mathrm{G} & \mathrm{H} & \mathrm{I} & 22.68 \\ \mathrm{G} & \mathrm{H} & \mathrm{I} & 22.67 \\ \mathrm{G} & \mathrm{H} & \mathrm{I} & 22.29 \\ \mathrm{G} & \mathrm{H} & \mathrm{I} & 22.13 \\ & \mathrm{H} & \mathrm{I} & 21.66 \\ & & \mathrm{I} & 21.16\end{array}$

${ }^{\psi}$ Means with different letters are significantly different

Table 9: Pairwise multiple comparison for the interaction between the nasal filter and flow rate under cyclic flow

Nasal Filter*Flow Rate

Naso Filter M,50

Eko Mask,50

Best Breath L,30

Naso Filter L, 85

Naso Filter S, 85

Best Breath L, 15

Best Breath M,85

Allerceptor, 15

Allerceptor,30

Best Breath M,15

Best Breath L,50

Best Breath M,50

Naso Filter L, 15

Naso Filter M,85

Best Breath S,50

Eko Mask,30

Eko Mask, 85

Allerceptor, 85

Naso Filter M,15

Naso Filter S,50

Best Breath M,30

Naso Filter M,30

Best Breath S,85

Woody Knows,30

Naso Filter L,30

Eko Mask, 15

Best Breath L,85

Mean Efficiency\% \%

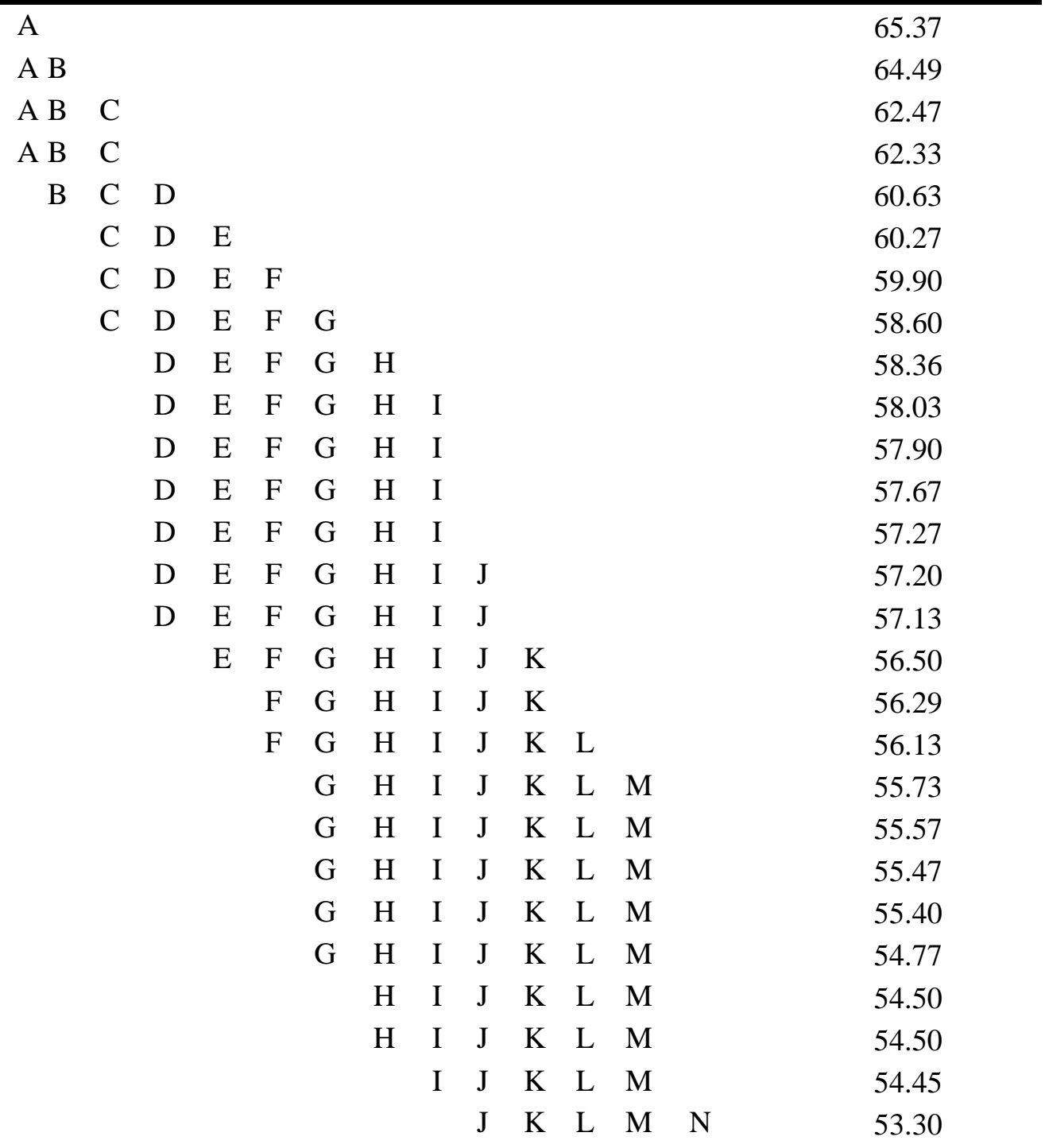


Naso Filter S,30

Best Breath S,30

Woody Knows,50

Woody Knows, 15

Best Breath S, 15

Naso Filter L,50

Naso Filter S, 15

Woody Knows, 85

Allerceptor,50
$\begin{array}{llll}\mathrm{K} & \mathrm{L} & \mathrm{M} & \mathrm{N}\end{array}$

K $\quad$ L $\quad M \quad N$

L M N

M N

M N

M N

$\mathrm{N} \mathrm{O}$

$\mathrm{N} \mathrm{O}$

$\mathrm{O}$
53.17

52.63

52.38

52.19

52.00

51.90

50.27

49.65

47.88

${ }^{\psi}$ Means with different letters are significantly different

\subsubsection{NaCl Result}

The mean efficiency values obtained for all nasal filters under constant and cyclic flow conditions are presented in Table 10 and 11. As shown in Table 10, under constant flow, all mean efficiency values were low, ranging between 2.20 to $29.51 \%$. The Best Breath L filter had the lowest mean efficiency of $2.20 \%$ and the Woody Knows filter had the highest mean efficiency of $29.51 \%$. Under cyclic flow, the mean efficiency values for all nasal filter types with different flow rates ranging from 30.75 to $52.36 \%$ (Table 11) These efficiencies were higher than those observed with constant flow. Woody Knows filter had the highest mean efficiency, $52.36 \%$ at $85 \mathrm{~L} / \mathrm{min}$, while Naso Filter S had the lowest efficiency, $30.75 \%$ at $30 \mathrm{~L} / \mathrm{min}$.

Table 10: Mean NaCl Efficiency \% for nasal filters under constant flow and different tested air flows

\begin{tabular}{ccccc}
\hline $\begin{array}{c}\text { Nasal Filter } \\
\text { Type }\end{array}$ & $\begin{array}{c}\text { Flow Type } \\
\text { and Flow } \\
\text { Rate (L/min) }\end{array}$ & $\begin{array}{c}\text { Mean Efficiency, \% } \\
\text { (Mean } \pm \text { SD)* }\end{array}$ & $\begin{array}{c}\text { Flow Type } \\
\text { and Flow } \\
\text { Rate (L/min) }\end{array}$ & $\begin{array}{c}\text { Mean Efficiency, \% } \\
\text { (Mean } \pm \text { SD) }\end{array}$ \\
\hline Allerceptor & Constant 15 & $3.62 \pm 2.08$ & Constant 50 & $6.23 \pm 3.74$ \\
& Constant 30 & $3.65 \pm 0.82$ & Constant 85 & $13.37 \pm 3.37$ \\
\hline $\begin{array}{c}\text { Best Breath } \\
\text { L }\end{array}$ & Constant 15 & $2.20 \pm 1.40$ & Constant 50 & $5.79 \pm 3.59$ \\
& Constant 30 & $4.95 \pm 2.75$ & Constant 85 & $6.23 \pm 1.81$ \\
\hline & Constant 15 & $3.08 \pm 0.48$ & Constant 50 & $7.19 \pm 2.03$
\end{tabular}




\begin{tabular}{cllll}
$\begin{array}{c}\text { Best Breath } \\
\text { M }\end{array}$ & Constant 30 & $6.20 \pm 3.38$ & Constant 85 & $15.97 \pm 4.09$ \\
\hline $\begin{array}{c}\text { Best Breath } \\
\text { S }\end{array}$ & Constant 15 & $21.01 \pm 23.37$ & Constant 50 & $11.83 \pm 4.68$ \\
& Constant 30 & $12.14 \pm 10.82$ & Constant 85 & $19.39 \pm 11.94$ \\
\hline EKO Mask & Constant 15 & $8.79 \pm 2.27$ & Constant 50 & $13.88 \pm 9.28$ \\
& Constant 30 & $12.68 \pm 0.98$ & Constant 85 & $20.18 \pm 11.46$ \\
\hline $\begin{array}{c}\text { Naso Filter } \\
\text { L }\end{array}$ & Constant 15 & $5.18 \pm 2.67$ & Constant 50 & $14.12 \pm 4.25$ \\
\hline $\begin{array}{c}\text { Naso Filter } \\
\text { M }\end{array}$ & Constant 30 & $9.21 \pm 4.80$ & Constant 85 & $20.09 \pm 1.35$ \\
\hline $\begin{array}{c}\text { Naso Filter } \\
\text { S }\end{array}$ & Constant 30 & $6.65 \pm 3.00$ & Constant 50 & $15.41 \pm 7.85$ \\
\hline $\begin{array}{c}\text { Woody } \\
\text { Knows }\end{array}$ & Constant 30 & $8.57 \pm 4.15$ & Constant 85 & $28.23 \pm 16.39$ \\
\hline
\end{tabular}

Table 11: Mean NaCl Efficiency \% for nasal filters under cyclic flow and different tested air flows

\begin{tabular}{ccccc}
\hline $\begin{array}{c}\text { Nasal Filter } \\
\text { Type }\end{array}$ & $\begin{array}{c}\text { Flow Type } \\
\text { and Flow } \\
\text { Rate (L/min) }\end{array}$ & $\begin{array}{c}\text { Mean Efficiency, } \\
\text { (Mean } \pm \text { SD) }\end{array}$ & $\begin{array}{c}\text { Flow Type } \\
\text { and Flow } \\
\text { Rate (L/min) }\end{array}$ & $\begin{array}{c}\text { Mean Efficiency, \% } \\
\text { (Mean } \pm \text { SD) }\end{array}$ \\
\hline Allerceptor & Cyclic 15 & $46.33 \pm 0.91$ & Cyclic 50 & $41.75 \pm 2.94$ \\
& Cyclic 30 & $41.21 \pm 6.36$ & Cyclic 85 & $44.30 \pm 5.57$ \\
\hline $\begin{array}{c}\text { Best Breath } \\
\text { L }\end{array}$ & Cyclic 15 & $48.64 \pm 2.72$ & Cyclic 50 & $42.71 \pm 2.90$ \\
\hline $\begin{array}{c}\text { Best Breath } \\
\text { M }\end{array}$ & Cyclic 30 & $40.53 \pm 4.41$ & Cyclic 85 & $40.75 \pm 3.51$ \\
\hline & Cyclic 30 & 45 & Cyclic 50 & $45.54 \pm 8.57$ \\
\hline & Cyclic 15 & $43.00 \pm 2.57$ & Cyclic 50 & $43.02 \pm 2.22$
\end{tabular}




\begin{tabular}{ccccc}
$\begin{array}{c}\text { Best Breath } \\
\text { S }\end{array}$ & Cyclic 30 & $39.66 \pm 1.68$ & Cyclic 85 & $33.24 \pm 0.81$ \\
\hline EKO Mask & Cyclic 15 & $36.76 \pm 4.73$ & Cyclic 50 & $41.13 \pm 5.00$ \\
& Cyclic 30 & $33.63 \pm 3.65$ & Cyclic 85 & $41.70 \pm 8.62$ \\
\hline $\begin{array}{c}\text { Naso Filter } \\
\text { L }\end{array}$ & Cyclic 15 & $40.11 \pm 5.66$ & Cyclic 50 & $35.13 \pm 8.24$ \\
\hline $\begin{array}{c}\text { Naso Filter } \\
\text { M }\end{array}$ & Cyclic 30 & $33.35 \pm 1.65$ & Cyclic 85 & $39.66 \pm 8.40$ \\
\hline $\begin{array}{c}\text { Naso Filter } \\
\text { S }\end{array}$ & Cyclic 30 & $39.52 \pm 7.87$ & Cyclic 50 & $37.69 \pm 6.74$ \\
\hline $\begin{array}{c}\text { Woody } \\
\text { Knows }\end{array}$ & Cyclic 30 & $33.86 \pm 2.94$ & Cyclic 85 & $39.30 \pm 7.00$ \\
\hline
\end{tabular}

ANOVA results showed that nasal filter type, concentration, and flow rate had a significant effect on efficiency under constant flow $(\mathrm{P}<0.05)$. In addition, the interaction between the variables showed no effect on the efficiency of the nasal filter (Table 12). As seen in Table 13, under cyclic conditions, ANOVA revealed that nasal filter type, flow rate, and the interaction between the nasal filter type and concentration were significant factors impacting efficiency $(\mathrm{P}<0.05)$. Concentration level, the interaction between nasal filter type and flow rate, and the interaction between the concentration level and flow rate showed no effect on the efficiency of nasal filter $(\mathrm{P}>0.05)$.

Table 12: Three-way ANOVA results for the efficiency of nasal filters under constant flow in NaCl study

\begin{tabular}{lcccc}
\hline Source & DF & Sum of Squares & F Ratio & P value \\
\hline Nasal Filter Type & 8 & 39.81 & 16.78 & $<.0001^{*}$ \\
Concentration & 2 & 4.15 & 7.00 & $0.0021^{*}$
\end{tabular}




\begin{tabular}{lcccc} 
Flow Rate & 3 & 24.35 & 27.38 & $<.0001^{*}$ \\
Nasal Filter Type*Concentration & 16 & 8.40 & 1.77 & 0.0644 \\
Nasal Filter Type*Flow Rate & 24 & 6.99 & 0.98 & 0.5029 \\
Concentration*Flow Rate & 6 & 1.35 & 0.76 & 0.6040 \\
\hline
\end{tabular}

Table 13: Three-way ANOVA results for the efficiency of nasal filters against $\mathrm{NaCl}$ under cyclic flow

\begin{tabular}{lcccc}
\hline Source & DF & Sum of Squares & F Ratio & P value \\
\hline Nasal Filter Type & 8 & 0.22 & 12.01 & $<.0001^{*}$ \\
Concentration & 2 & 0.008 & 1.92 & 0.1565 \\
Flow Rate & 3 & 0.029 & 4.28 & $0.0093^{*}$ \\
Nasal Filter Type*Concentration & 16 & 0.082 & 2.21 & $0.0171^{*}$ \\
Nasal Filter Type*Flow Rate & 24 & 0.054 & 0.98 & 0.5020 \\
Concentration*Flow Rate & 6 & 0.006 & 0.49 & 0.8116 \\
\hline
\end{tabular}

The pairwise multiple comparison results for nasal filter types, concentration levels, and flow rates under constant flow are presented in Table 14 and the results for nasal filter types and flow rates under cyclic flow are presented in Table 15. The pairwise multiple comparison for the interaction between the nasal filter type and concentration level under cyclic flow is listed in Table 16. Woody Knows filter had the highest efficiency value under both constant (24.50\%) and cyclic (49.99\%) flow (Tables 14 and 15). The efficiency measured at a concentration level of 400,000 particles $/ \mathrm{cm}^{3}$ was significantly higher than efficiencies measured at concentrations of 100,000 and 200,000 particles $/ \mathrm{cm}^{3}(\mathrm{P}<0.05)$. Also, the pairwise comparison showed that efficiencies measured at each flow rate were significantly different (Table 14). Under cyclic flow, $15 \mathrm{~L} / \mathrm{min}$ flow rate had the highest mean efficiency $(42.83 \%)$ and $30 \mathrm{~L} / \mathrm{min}$ flow rate had the lowest mean efficiency (38.38\%). In Table 15, the multiple comparison results showed that there was no difference between the flow rates 15,50 , and $85 \mathrm{~L} / \mathrm{min}$. In Table 16, the interaction between the nasal filter type and concentration level under cyclic flow showed that the mean efficiency for each nasal filter 
depends on concentration level and 200,000 particles $/ \mathrm{cm}^{3}$ concentration level was the largest between the levels of concentration and 400,000 particles $/ \mathrm{cm}^{3}$ was the lowest.

Table 14: Pairwise multiple comparisons: mean $\mathrm{NaCl}$ efficiency among nasal filters and flow rate under constant air flow

\begin{tabular}{|c|c|c|c|}
\hline Variable & Mean Efficiency\% & Levels & Grouping $\psi$ \\
\hline \multirow{9}{*}{ Filter Type } & 24.50 & Woody Knows & A \\
\hline & 16.10 & Best Breath $\mathrm{S}$ & B \\
\hline & 14.72 & Eko Mask & B \\
\hline & 13.89 & Naso Filter M & B \\
\hline & 12.58 & Naso Filter S & B \\
\hline & 12.15 & Naso Filter L & B \\
\hline & 8.11 & Best Breath M & $\mathrm{C}$ \\
\hline & 6.72 & Allerceptor & C D \\
\hline & 4.70 & Best Breath L & $\mathrm{D}$ \\
\hline \multirow{3}{*}{ Concentration } & 15.28 & 400 & $\mathrm{~A}$ \\
\hline & 11.94 & 100 & B \\
\hline & 10.60 & 200 & B \\
\hline \multirow{4}{*}{ Flow Rate } & 19.19 & 85 & $\mathrm{~A}$ \\
\hline & 13.05 & 50 & B \\
\hline & 9.86 & 30 & $\mathrm{C}$ \\
\hline & 8.34 & 15 & $\mathrm{D}$ \\
\hline
\end{tabular}

${ }_{\psi}$ Means with different letters are significantly different

Table 15: Pairwise multiple comparisons: mean $\mathrm{NaCl}$ efficiency among nasal filters and flow rate under cyclic air flow

\begin{tabular}{|c|c|c|c|}
\hline Variable & Mean Efficiency \% & Levels & Grouping $\psi$ \\
\hline \multirow{9}{*}{ Filter Type } & 49.99 & Woody Knows & $\mathrm{A}$ \\
\hline & 45.93 & Best Breath M & B \\
\hline & 43.40 & Allerceptor & B C \\
\hline & 43.16 & Best Breath L & B C \\
\hline & 39.73 & Best Breath S & C D \\
\hline & 38.31 & Eko Mask & D E \\
\hline & 37.60 & Naso Filter M & $\mathrm{DE}$ \\
\hline & 37.07 & Naso Filter L & $\mathrm{DE}$ \\
\hline & 35.07 & Naso Filter S & $\mathrm{E}$ \\
\hline \multirow[t]{3}{*}{ Flow Rate } & 42.83 & 15 & $\mathrm{~A}$ \\
\hline & 41.68 & 85 & $\mathrm{~A}$ \\
\hline & 41.67 & 50 & A \\
\hline
\end{tabular}


${ }^{\psi}$ Means with different letters are significantly different

Table 16: Pairwise multiple comparison for the interaction between the nasal filter and concentration level under cyclic flow

\begin{tabular}{|c|c|c|c|c|c|c|}
\hline Nasal Type*Concentration & & & & & & Mean Efficiency $\% \psi$ \\
\hline Woody Knows,200 & A & & & & & 53.00 \\
\hline Woody Knows, 100 & A & $\mathrm{B}$ & & & & 52.09 \\
\hline Best Breath M,100 & A & B & $\mathrm{C}$ & & & 49.19 \\
\hline Best Breath L, 100 & A & $\mathrm{B}$ & $\mathrm{C}$ & $\mathrm{D}$ & & 45.01 \\
\hline Woody Knows,400 & A & B & $\mathrm{C}$ & $\mathrm{D}$ & & 44.87 \\
\hline Allerceptor,200 & A & $\mathrm{B}$ & $\mathrm{C}$ & $\mathrm{D}$ & & 44.79 \\
\hline Best Breath M,200 & A & $\mathrm{B}$ & $\mathrm{C}$ & $\mathrm{D}$ & & 44.50 \\
\hline Best Breath M,400 & A & $\mathrm{B}$ & $\mathrm{C}$ & $\mathrm{D}$ & & 44.10 \\
\hline Best Breath L,400 & A & $\mathrm{B}$ & $\mathrm{C}$ & $\mathrm{D}$ & $\mathrm{E}$ & 43.56 \\
\hline Allerceptor,400 & A & B & $\mathrm{C}$ & $\mathrm{D}$ & $\mathrm{E}$ & 43.09 \\
\hline Naso Filter L,400 & A & $\mathrm{B}$ & $\mathrm{C}$ & $\mathrm{D}$ & $\mathrm{E}$ & 42.69 \\
\hline Allerceptor, 100 & A & B & $\mathrm{C}$ & $\mathrm{D}$ & $\mathrm{E}$ & 42.33 \\
\hline Naso Filter M,200 & A & $\mathrm{B}$ & $\mathrm{C}$ & $\mathrm{D}$ & $\mathrm{E}$ & 41.60 \\
\hline Naso Filter S,200 & A & B & $\mathrm{C}$ & $\mathrm{D}$ & $\mathrm{E}$ & 41.28 \\
\hline Best Breath L,200 & A & B & $\mathrm{C}$ & $\mathrm{D}$ & $\mathrm{E}$ & 40.91 \\
\hline Best Breath S,400 & A & B & $\mathrm{C}$ & $\mathrm{D}$ & $\mathrm{E}$ & 40.21 \\
\hline Best Breath S,100 & A & B & $\mathrm{C}$ & $\mathrm{D}$ & $\mathrm{E}$ & 40.18 \\
\hline Eko Mask,200 & & B & $\mathrm{C}$ & $\mathrm{D}$ & $\mathrm{E}$ & 39.43 \\
\hline Best Breath S,200 & & B & $\mathrm{C}$ & $\mathrm{D}$ & $\mathrm{E}$ & 38.81 \\
\hline Naso Filter M,100 & & & $\mathrm{C}$ & $\mathrm{D}$ & $\mathrm{E}$ & 38.57 \\
\hline Eko Mask,400 & & & $\mathrm{C}$ & $\mathrm{D}$ & $\mathrm{E}$ & 38.52 \\
\hline Eko Mask, 100 & & & $\mathrm{C}$ & $\mathrm{D}$ & $\mathrm{E}$ & 36.97 \\
\hline Naso Filter L,200 & & & $\mathrm{C}$ & $\mathrm{D}$ & $\mathrm{E}$ & 36.00 \\
\hline Naso Filter S,100 & & & & $\mathrm{D}$ & $\mathrm{E}$ & 33.35 \\
\hline Naso Filter M,400 & & & & $\mathrm{D}$ & $\mathrm{E}$ & 32.61 \\
\hline Naso Filter L,100 & & & & $\mathrm{D}$ & $\mathrm{E}$ & 32.51 \\
\hline Naso Filter S,400 & & & & & $\mathrm{E}$ & 30.59 \\
\hline
\end{tabular}

${ }^{\psi}$ Means with different letters are significantly different 


\subsubsection{Efficiency distribution of challenge ETS and $\mathrm{NaCl}$}

The penetration through the nasal filter was determined as the ratio of $\mathrm{C}_{\text {in }}$ to $\mathrm{C}_{\text {out }}$, and efficiency of nasal filter was calculated by subtracting nasal filter penetration from one under constant and cyclic flow. Most of the particles detected by the NanoScan device were between the particle size of 11.5 to $154 \mathrm{~nm}$. The size range of $11.5-154 \mathrm{~nm}$ was divided into ten channels by the NanoScan device to determine the size range of the most penetrated particles (Peak).

In the ETS experiment, the efficiency of the nasal filters calculated from the penetrating particles during constant conditions was much lower than cyclic condition under all flow rates, as shown in Figures 4 and 5.

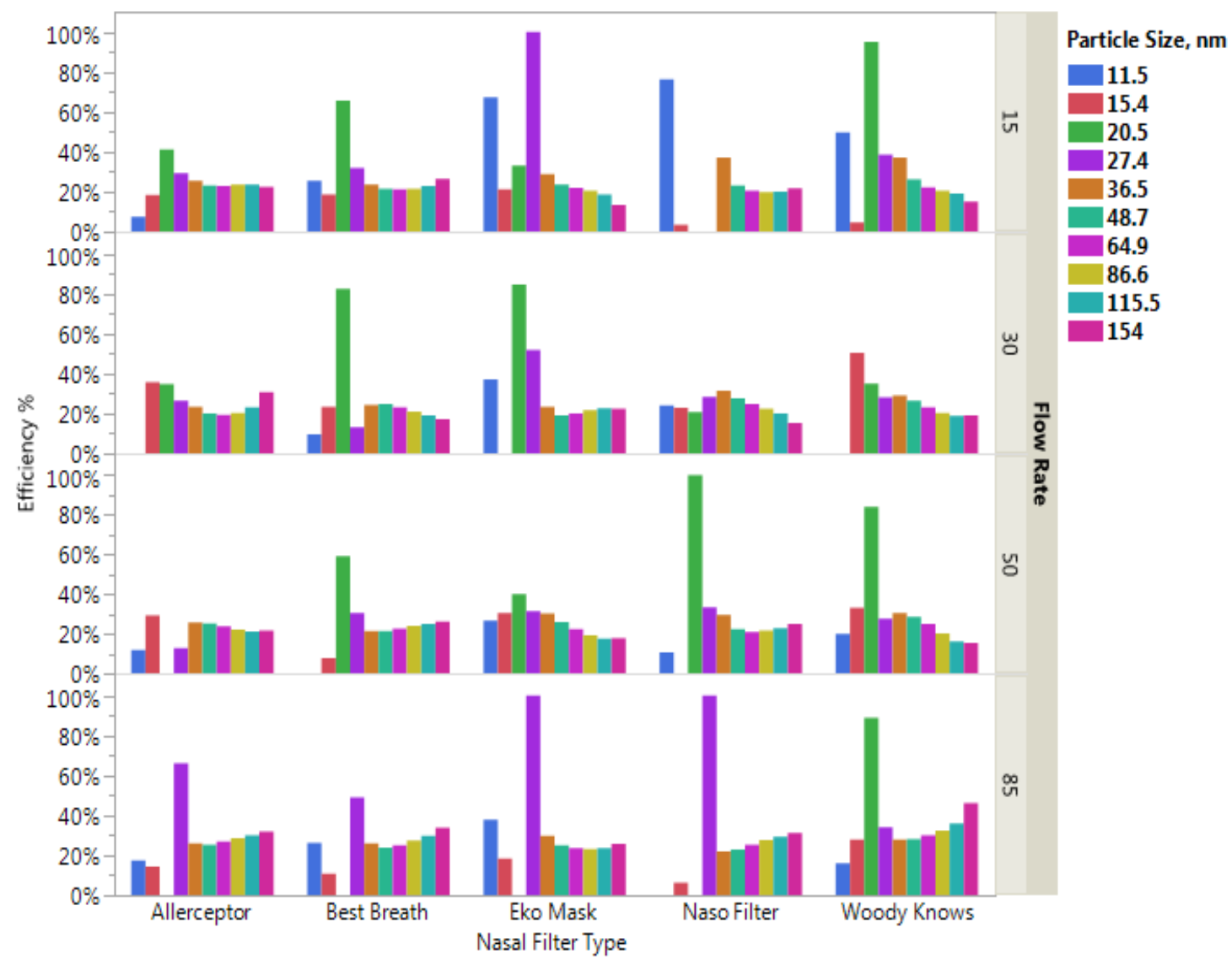

Figure 4: Particle size distribution of challenge ETS under constant flow with four different flow rates 
In constant and cyclic conditions, the highest efficiency occurred in the size range of 20.5$27.4 \mathrm{~nm}$, while the lowest efficiency occurred in the size range of 115.5-154 nm under constant flow and in the size range of 11.5-15.4 nm under cyclic flow. In the size range of 20.5-27.4 nm, the efficiency under constant flow was more than $40 \%$ and ranged between 60 to $80 \%$ in most nasal filters; meanwhile it was more than $60 \%$ and ranged between 65 to $80 \%$ in the majority of nasal filters under cyclic flow. Under constant flow and in the size range of 115.5-154 nm, the efficiency was less than $20 \%$. Under cyclic flow and in the size range of $11.5-15.4 \mathrm{~nm}$, the efficiency was ranged between 40 to $60 \%$.

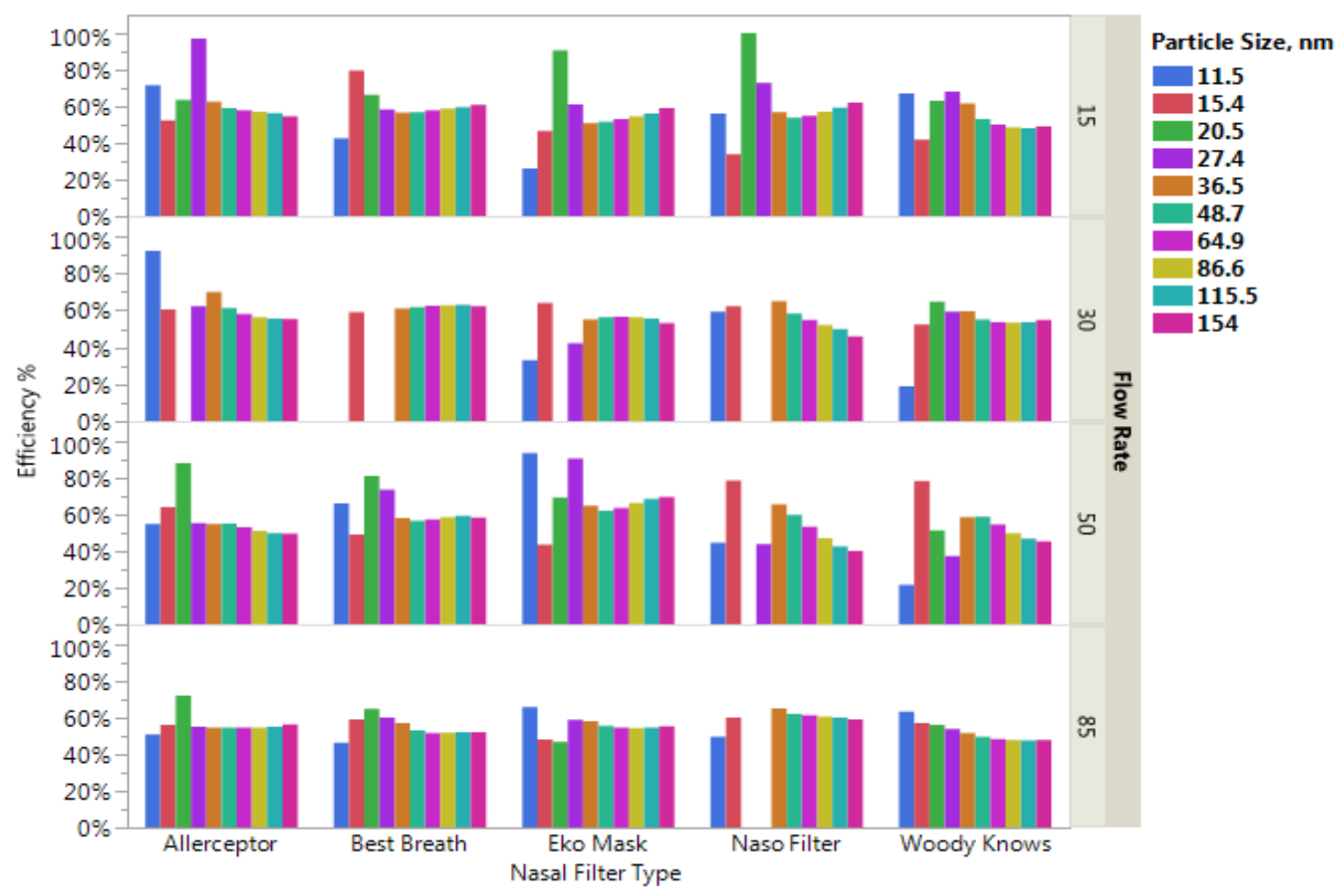

Figure 5: Particle size distribution of challenge ETS under cyclic flow with four different flow rates

In $\mathrm{NaCl}$ experiment, the highest efficiency of nasal filters calculated from penetrated particles that detected by the NanoScan with different flow rates was in the size range of 115.5- 
$154 \mathrm{~nm}$ under constant flow and 11.5-20.5 nm under cyclic flow, while the lowest efficiency was ranged between 48.7-64.9 nm under constant and cyclic flow (Figures 6 and 7). Under constant flow, the highest efficiency of the nasal filters was less than $40 \%$ and ranged between 20 to $40 \%$ in the size range of $115.5-154 \mathrm{~nm}$, and the lowest efficiency ranged between $0-10 \%$ in the size range of 48.7-64.9 nm. Meanwhile, under cyclic flow, the highest and lowest efficiency were more than constant flow; the highest efficiency ranged between 40 to $60 \%$ in most nasal filters within the size range of $11.5-20.5 \mathrm{~nm}$, while the lowest efficiency ranged between $20-40 \%$ in the size range of $48.7-64.9 \mathrm{~nm}$.

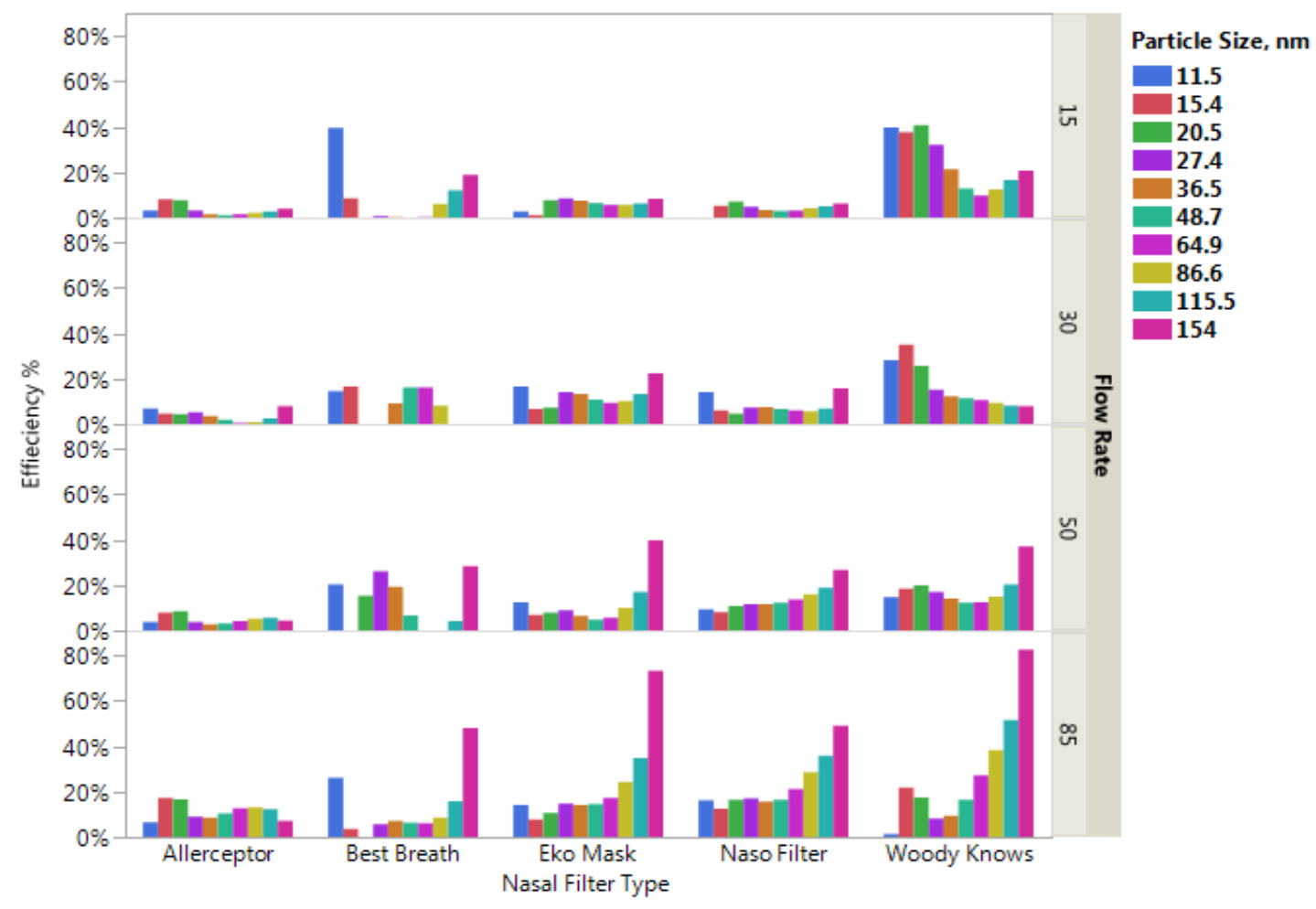

Figure 6: Particle size distribution of challenge $\mathrm{NaCl}$ under constant flow with four different flow rates 


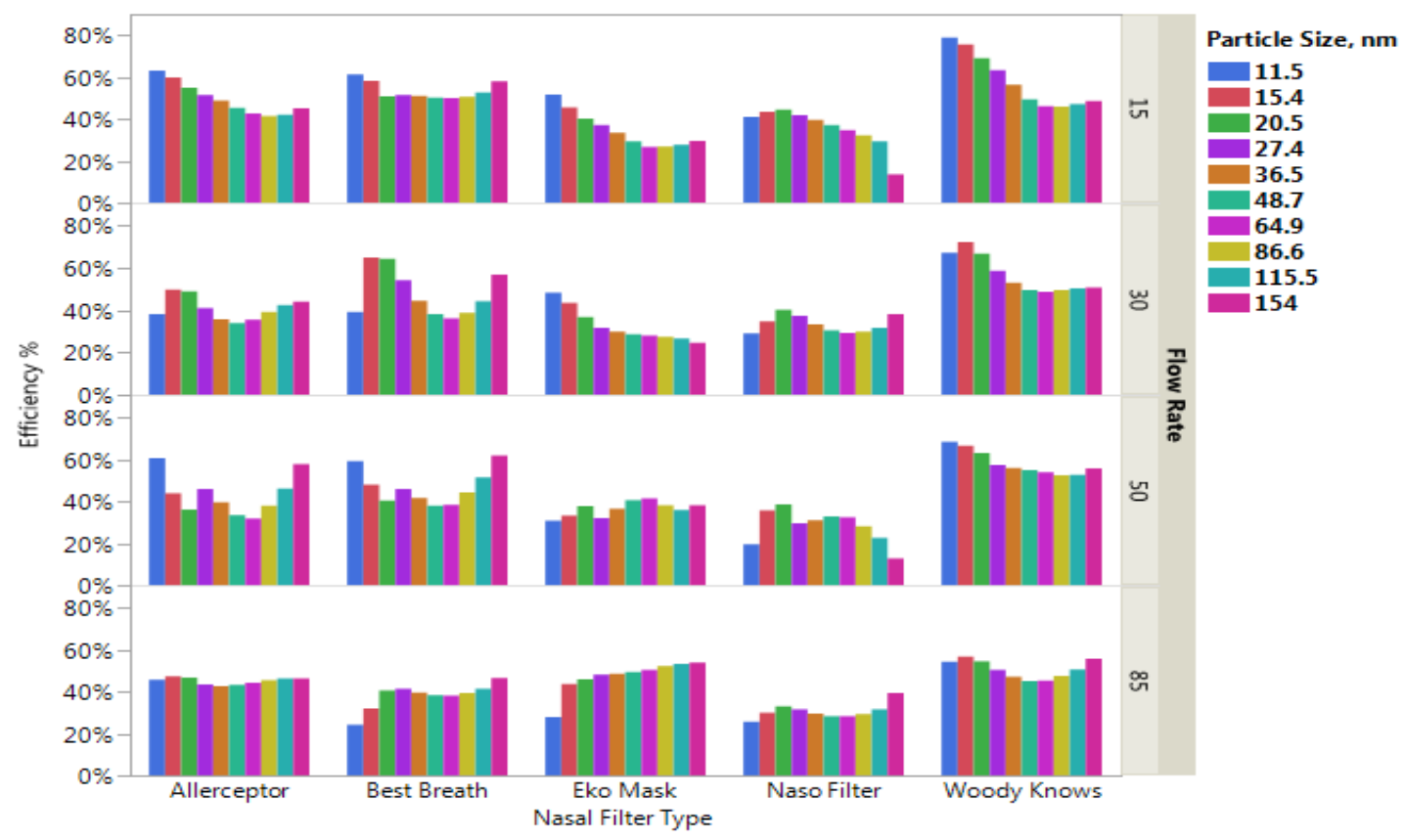

Figure 7: Particle size distribution of challenge NaCl under cyclic flow with four different flow rates

\subsection{Discussion:}

Innovative nasal filters are designed to reduce exposure to air pollution. Results of this study revealed that all tested nasal filters offered the user very limited protection against ETS and $\mathrm{PM}_{1}$ particles, generally just a protection factor of 2 or less. Under a constant flow condition for both ETS and $\mathrm{PM}_{1}$ aerosol challenges, as the test flow rate increased, the mean efficiency value increased significantly $(\mathrm{P}<0.05)$; there was a significant difference between the four flow rates' resulting mean efficiency $(85,50,30$, and $15 \mathrm{~L} / \mathrm{min})$. A similar conclusion has been drawn by $\mathrm{He}$ et al. (2013); He et al. tested P100 half-mask respirators under constant flow with three flow rates (30, 85, and $135 \mathrm{~L} / \mathrm{min}$ ) against plastic combustion and found that the penetration decreases with increasing flow rate. Meanwhile, under cyclic flow, the results showed that increasing the flow rate does not always raise the efficiency. In our ETS study, $50 \mathrm{~L} / \mathrm{min}$ produced the highest mean efficiency; there was no difference between 50 and $85 \mathrm{~L} / \mathrm{min}$ and no difference between 30 and 15 
$\mathrm{L} /$ min. In the $\mathrm{NaCl}$ study, $15 \mathrm{~L} /$ min produced the highest mean efficiency; there was no difference between 15,85 , and $50 \mathrm{~L} / \mathrm{min}$.

In the ETS study, under different flow rates, the mean efficiency values ranged between 20-30\% during constant flow, while the values ranged between 45-65\% during cyclic flow. Similar results were observed for the $\mathrm{NaCl}$ study. The $\mathrm{NaCl}$ study showed relatively lower efficiency values than the ETS study; the efficiency values ranged between 2-29\% during constant flow and $33-53 \%$ during cyclic flow. Overall, the mean efficiency values under cyclic flow were found to be approximately twice those found under constant flow. The reason behind this difference is that with cyclic conditions during the breathing process, no particles enter during exhalation, which accounts for about half of the breathing duration. A HEPA filter installed between the designed system and the breathing simulator prevents the particles in the return flow from entering the nasal filter. This finding is consistent with He et al. (2013). He et al. found that at $30 \mathrm{~L} / \mathrm{min}$ flow rate, the penetration under cyclic flow was lower than the penetration under constant flow.

Filtration efficiency is significantly affected by the particle size (Lee and Liu, 1980). In ETS, the increase in filtration velocity and fiber volume fraction means increased filter efficiency. A study conducted by Overton (1973) on the filtration mechanisms with flow velocity indicated that at $35 \mathrm{~cm} / \mathrm{s}$ velocity, the relative contribution to filtration by diffusion was $40 \%$ and by interception was $60 \%$. Time and concentration can change the size of smoke particles. Smoke contains volatile components and evaporation gradually reduces the diameter of the particle. The size of ETS particles can decrease with evaporation, and can increase with coagulate (Hinds, 1978; National Research Council, 1986). In the ETS study, the highest efficiency achieved with the nasal filters occurred at the highest concentration $\left(400,000\right.$ particles $\left./ \mathrm{cm}^{3}\right)$ and gradually decreased from the highest to the lowest concentration (from 400,000 to 100,000 particles $/ \mathrm{cm}^{3}$ ) over time. One 
possible reason for this observation is the change in particle size of the cigarette smoke over the time of the tests. After the cigarette was extinguished and at a concentration level of 400,000 particles $/ \mathrm{cm}^{3}$, the efficiency of the nasal filter was higher because the particles were still large. Over time, the evaporation of volatile components helped to gradually reduce the size of the particles, which enabled them to more readily penetrate the nasal filters. Also, one other factor that may affect efficiency and increase the penetration of ETS is the strength of cigarette tobacco. A study done by Braun et al. (2019) on four different types of one brand of cigarette (Marlboro) with different strength (tar, nicotine, and carbon monoxide) showed that the higher tobacco strength (amounts of tar, nicotine, and carbon monoxide), the more particulate the cigarette produced.

The mean efficiency values found in this study indicated that nasal filters may offer limited protection against ETS and $\mathrm{PM}_{1}$ particles. For comparison, generally, the surface areas of filtering facepiece respirators are between 10,000-30,000 $\mathrm{mm}^{2}$ (Chen et al., 2014), while the surface areas of the tested nasal filters ranged between $120-500 \mathrm{~mm}^{2}$, which was much smaller than the FFR (Table 17). Therefore, during inspiratory cyclic flow or constant flow, the face velocity of airflow that passes through the nasal filter is much higher than NIOSH approved negative pressure particulate respirators. The inverse relationship between filter efficiency and face velocity has been documented in numerous research studies (He et al., 2014; Mukhametzanov et al., 2016; Zhou and Cheng, 2016; Wang et al., 2017). As all have documented, when the face velocity increases, the efficiency of the filter decreases because the higher face velocity reduces the length of time for the particles to pass through the respirator filter, which leads to a lower probability of particles being captured by the filtering mechanisms of diffusion and electrostatic attraction.

Table 17: The surface area for each nasal filter 


\begin{tabular}{cc}
\hline Allerceptor & 410.4 \\
EKO Mask & 380.1 \\
Woody Knows & 120 \\
Naso Filter L & 380 \\
Naso Filter M & 330 \\
Naso Filter S & 250 \\
Best Breath L & 531 \\
Best Breath M & 314.1 \\
Best Breath S & 201 \\
\hline
\end{tabular}

In these two studies, we found that the efficiency of the nasal filters under cyclic flow was larger than constant flow in both studies. In the ETS study, the lowest efficiency of constant and cyclic flow was less than $20 \%$ and between 40 to $60 \%$ in the size range of $115.5-154 \mathrm{~nm}$ and 11.5 $15.4 \mathrm{~nm}$, respectively, while in $\mathrm{NaCl}$ study the lowest efficiency under constant and cyclic flow was 0 to $10 \%$ and 20 to $40 \%$ in the size range of $48.7-86.6 \mathrm{~nm}$, respectively. Several studies have reported that most penetration particle size (the lowest efficiency) occurred in the size range of less than $100 \mathrm{~nm}$ for N95 FFR (Huang et al. 2007; Rengasamy et al. 2009; He et al. 2013). He et al found that the most penetrating particle size (the lowest efficiency) for the N95 FFR with different flow rates $(15,55$, and $85 \mathrm{~L} / \mathrm{min})$ was between $30-40 \mathrm{~nm}$. Another study done by He $e t$ al (2013) indicated that the most penetrating particle size (the lowest efficiency) for the P100 FFR fell between the range size of 50-200 $\mathrm{nm}$.

The assigned protection factor (APF) is used by OSHA to determine the expected minimum protection level provided by the respirator against external contaminants during wear, based on the appropriate respiratory protection program. Fit factor is the ratio of challenge aerosol concentration outside the respirator/mask $\left(\mathrm{C}_{\mathrm{out}}\right)$ to the concentration inside the respirator/mask $\left(\mathrm{C}_{\text {in }}\right)\left(\right.$ Fit Factor $\left.=C_{\text {out }} / C_{\text {in }}\right)$. According to ANSI Z88.10, a fit factor must be at least 10 times larger than APF in negative pressure respirators. Different types and sizes of respirators have several levels of APF and fit factor; the half-mask respirators including the N95 FFR has an APF 
of 10 and the passing fit factor is 100 . That means a N95 FFR reduces the concentration of the aerosol to $1 / 10$ of indoor environment, which is equivalent to blocking $90 \%$ of the air contaminants from being inhaled. In these two studies, the efficiency of five different nasal filters were calculated against ETS and $\mathrm{NaCl}$ particles $\left(\mathrm{PM}_{1}\right.$ and $\left.\mathrm{PM}_{2.5}\right)$. Nasal filter are not approved by NIOSH to be used against aerosolized particles and do not have an APF issued by OSHA. In both studies, the efficiency of the nasal filters was relatively low and the maximum efficiency under constant flow was less than $50 \%$, which is equivalent to a fit factor of 2 or less. With this low efficiency $(<50 \%)$ nasal filters cannot control serious exposure against challenge aerosols (ETS and $\mathrm{NaCl})$ that contain small particle sizes $(0.01-1 \mu \mathrm{m})$ and cannot be used for workers who are exposed to ETS as casino workers. Nasal filters may be suitable for personal use or for use against pollen allergy, which contains large particles $\left(>\mathrm{PM}_{2.5}\right)$ that may raise the efficiency of the nasal filters.

In these two studies, four flow rates $(15,30,50$, and $85 \mathrm{~L} / \mathrm{min})$ were tested under constant and cyclic conditions. These flow rates represented breathing at light, medium, and high workloads (Lafortuna et al., 1984; Anderson et al., 2006). The use of nasal filters should be reserved for light workloads in order to avoid breathing through the mouth. However, in these two studies we wanted to compare the different flow rates and the efficiency of nasal filters and place our findings in conversation with previous studies. Several previous studies have used different flow rates, including those modeling high workload to reveal their effect on respirator efficiency, too ((Balazy et al., 2006; Eninger et al., 2008; Rengasamy and Eimer, 2011; He et al. 2013).

\subsection{Conclusion:}

In the two studies, five nasal filters (two of them in different sizes) were evaluated as to their mean efficiency values with respect to the concentration level, flow type, and flow rate. Some 
of the factors had a significant effect on the efficiency of the nasal filter. Although nasal filters have good application prospects in reducing exposure to air pollution, the mean efficiency value was relatively low $(<60 \%)$ in both constant and cyclic flow regimes. In both studies, the low mean efficiency value indicates that exposure protection offered by nasal filters against particles is limited. Nasal filter type, concentration level, and flow rates significantly impacted the efficiency. Big differences in the mean efficiency were found between constant and cyclic flow conditions. Under cyclic flow condition, the efficiency was found to be twice the efficiency obtained under constant flow in both studies. Overall, the findings in this study suggest that to avoid mouth breathing, nasal filters may only be appropriate during light-effort working conditions and with very low exposures. More initiative must be taken by manufacturers to improve the filtration efficiency of nasal filters, such as improve the filter membrane to improve filtration efficiency and withstand high flow rates while taking into account the user's comfort.

A limitation of the study is that the nasal filters were completely and fully sealed, while there may be seal leakage during actual use. Also, a self-designed nasal filter testing system was used in these two studies and this system is not approved for the use of testing by OSHA or NIOSH. Currently there are no approved nasal filter testing systems. Future research could seek to develop an approved testing system and could then duplicate our experiment. 


\section{Chapter 2}

(Study 3): Evaluate users' experiences of comfort, suitability, exertion, and total assessment of different types of nasal filters when performing various tasks.

\subsection{Introduction}

The implementation of personal protective equipment (PPE) by employers helps protect workers from health and safety hazards in the workplace. PPE includes respirators, safety helmets, gloves, eye protection, high-visibility clothing, and safety footwear. Respiratory protective equipment is the most important means of protecting the respiratory tract from air contaminated with toxic materials. Under the Respiratory Protection Standard (29 CFR 1910.134), OSHA requires appropriate respirators to be used if air is contaminated with harmful dusts, fogs, fumes, mists, gases, smokes, sprays, or vapors. OSHA requires five million employees to wear respirators in more than 1.3 million workplaces in the United States (Purdy, 2019).

One of the most important fields in which workers should wear a respirator and other personal protection equipment (PPE) is health care. The health care work environment poses a risk to workers because it may contain aerosol-transmissible diseases (ATDs) such as SARS in 2003, influenza in 2009, Ebola in 2014 and CoVid19 in 2020. Thus, OSHA requires all health care facilities to provide employee protection against blood-borne and airborne pathogens. The National Institute for Occupational Safety and Health (NIOSH) and the Centers for Disease Control and Prevention (CDC) recommend that certified respirator be used as an effective way to reduce the risk of disease transmission in health care workers. 
Air-purifying respirators and atmosphere-supplying respirators are the two major classes of respirators that are used by workers. Air-purifying respirators use filters and cartridges to remove contaminants from inhaled air, whereas atmosphere-supplying respirators provide breathable air from a non-polluted source (OSHA, 2002).

One of the most common types of air-purifying respirator is the N95 filtering face piece respirator (FFR). A common type of atmosphere-supplying respirator is the self-contained breathing apparatus (SCBA), which is considered to provide the highest level of respiratory protection that can be achieved. Many factors can be used to determine the degree of protection provided by respirators. The most important of these are the assigned protection factor (APF), the maximum use concentration (MUC), and the total inward leakage (TIL).

OSHA uses the APF to determine the efficacy of the respiratory protection program implemented by the employer. The APF measures the efficiency of respirators by determining the level of respiratory protection that the respirator provides to the employee. N95 respirators have an APF of 10; PAPRs have an APF of 25; and SCBA have an APF of 10,000.

The MUC is another approach to assessing the efficiency of respirators. MUC means the maximum concentration of polluted air that the employee can be exposed to and still achieve adequate protection when wearing an appropriate respirator. This can be determined by multiplying the APF for a respirator by the OSHA permissible exposure limit (PEL) (Steelnack, 2007). The total inward leakage (TIL) is another factor used to evaluate the efficiency of respirators and is determined mathematically as the ratio of the concentration external to the respirator and the concentration inside the breathing cavity of the respirator. Several studies have determined the efficiency of respirators by using TIL (Rengasamy et al., 2011; He et al., 2013). 
Experts have researched several types of respirators including N95 FFRs, surgical masks, and PAPRs to determine their efficiency (Richardson et al., 2010; Bischoff, 2017). One of the most important factors that affect the efficiency of respirators is its fit. A respirator fit test must be done to determine the appropriate respirator size, type, make, and model of for the user. In addition, the protection that the respirator provides can be affected by physiologically and psychologically conditions (Szeinuk et al., 2000), so evaluating the user's experience is an important factor in measuring the comfort of the respirator.

OSHA had provided guidance for conducting quantitative and qualitative fit tests. Their guidance include asking the user to select the most acceptable respirator, informing the user that each respirator has a different shape, size, and fitting characteristics, giving the user enough time to determine the comfort of the respirator once it is donned and having the user do several head and face movements while the fit test is being conducted. The head and face movements include normal breathing, deep breathing, turning the head side to side, moving the head up and down, grimacing and talking.

Wearing a surgical mask has been reported to increase the wearer's discomfort over time (Zhu et al., 2014). Li et al. studied ten participants to find out the effects of wearing a surgical mask and N95 respirator on heart rate and thermal stress. The results showed that participants had significantly lower average heart rates when wearing surgical masks than when wearing N95 respirators; however, the skin surface temperature under the surgical mask was significantly higher than with the N95 respirator. A study of twenty subjects using a treadmill for one hour while wearing a surgical mask showed an increase in heart rate and temperature of the skin covered by the mask (Roberge et al. 2012). Surgical masks may affect the surgeons' oxygen saturation of 
hemoglobin during the surgery. This was reported in a study done by Beder et al. for fifty-three surgeons showed that the blood oxygen levels $\left(\mathrm{SpO}_{2}\right)$ decreased for the surgeons aged over 35 .

The N95 respirator is certified to filter out at least $95 \%$ of 0.3 -micron particles. Frequent complaints from users of the N95 FFRs are related to facial heat. In one study, participants were asked to perform a fit test with $\mathrm{N} 95$ respirators and then walk on a treadmill for one to two hours. The results showed that facial skin temperature under the FFR, which was monitored with dermal sensors, significantly increased (Roberge et al., 2012). Wearing an N95 respirator for long periods of time has been reported by health care workers (HCW) to cause headaches. A study conducted with a survey of $212 \mathrm{HCW}$ showed that wearing an N95 for more than four hours increased headaches (Lim et al. 2006). Moreover, another study of HCWs showed that wearing an N95 respirator for four hours caused tiredness, increased the partial pressure of carbon dioxide $\left(\mathrm{PaCO}_{2}\right)$, and decreased blood oxygen levels (SpO2) (Kao et al., 2010). A study has also shown that N95 FFR can reduce speech intelligibility (SI) by 17\% (Palmiero et al., 2016). This is a problem because clear communication between HCWs is important, especially in critical situations such as emergencies.

The comfort level of wearing a powered air purifying respirator (PAPR) is higher than that for other respirators; so many employees prefer to wear a PAPR for respiratory protection, especially health care workers. The comfort levels are high with PAPRs use because of reduced breathing effort, and a supply of airflow over the face. However, there are disadvantages of using PAPRs. A study showed that the battery pack required for the PAPR is often heavy, needs to charge for a long time, and is noisy (Lenhart et al., 2004). Moreover, one study examined the comfort of PAPRs by requiring twelve participants to wear five different types of respirators (N95 and PAPR) and walk on the treadmill for one hour. They found that using PAPRs increased 
perceptions of eye dryness and facial temperature (Powell et al., 2017). Also, Johnson et al. required sixteen subjects to walk on a treadmill while wearing a tight-fitting PAPR with a DC power supply which had flow rates of $0-100 \%$ of rated maximum blower capacity of $110 \mathrm{~L} / \mathrm{min}$. The results showed that an inadequate blower flow rate decreases performance time and produces discomfort to the wearer.

At rest condition, $90 \%$ of the air that humans breathe is through their nose, which filters particulate matter by the vibrissae hairs and adds moisture and warmth to the air inhaled to the lungs (Camner and Bakke, 1980; Lumb, 2016). Innovative nasal filters are designed to increase the nasal filtration of air particles entering through the nose by inserting two small nasal filters into the nostrils. There are many advantages of a nasal filter, including that it is lightweight, invisible from the outside, and makes oral communication easier. However, nasal filters may cause a nasal twang to its users, which may generally disappear within a day or two (Pasricha, 1981). There are a few studies about the efficiency of the nasal filters for protection against pollen allergy (D'Amato et al., 2013; Kenney et al., 2015; Kenney et al., 2016). However, no research has been done on filtration efficiency of nasal filters against submicron air particles or how comfortable they are while worn. Using an evaluation model of user's experiences with nasal filters, the current study seeks to evaluate the comfort of nasal filters in indoor and outdoor environments. The results will address the acceptability of nasal filters from the users' experiential evaluations.

\subsection{Methods}

\subsubsection{Subject Recruitment}

Eight subjects from twenty-five to forty-five years of age were recruited for this experiment. Subjects were non-smokers, volunteers, students at WVU, and free of respiratory or thoracic disease. All experiments were conducted at the respiratory lab, Mineral Resources 
Building, West Virginia University. Approvals from the Institutional Review Board (IRB) at the West Virginia University was obtained (IRB approval number 1906614987).

\subsubsection{Experimental Setup}

Data collection occurred in the respiratory laboratory room 246 of the Mineral Resources Building. Participants performed tasks in Room 246 and outside the building. After putting on the nasal filter, the subjects were asked to perform some tasks (moving the head from side-to-side, moving the head up and down, normal breaths, deep breaths, bending over, and walking), both inside and outside the building. These tasks were performed over a ten-minute period (Table 18). The temperature of the room was $22^{\circ} \mathrm{C}$.

Table 18: Summary of experimental tasks

\begin{tabular}{c|ll}
\hline \multicolumn{2}{c}{ Variable } & \multicolumn{1}{c}{ Levels } \\
\hline Nasal Filter & \multicolumn{1}{c}{ 5 nasal filter } \\
\hline Subject & \multicolumn{1}{c}{ 8 human subjects } \\
\hline & 1. Moving the head from side-to-side \\
& 2. Moving the head up and down \\
Tasks & 3. Normal breaths \\
& 4. Deep breaths \\
& 5. Bending over \\
& 6. Walking \\
\hline
\end{tabular}

\subsubsection{Tested Nasal Filter}

Filtration efficiency testing of the nasal filters was discussed in section (1.2.1 Tested Nasal Filters). For nasal filters that had different sizes (small, medium, and large), participants were asked to choose the appropriate nasal filter size that was examined by the co-investigator after being worn by the participant to ensure that it perfectly fits the nostril. In figure 8 , the size that co- 
investigator chose for the participant was size small, because size large was too big to fit the nostril and size medium was to tight and the participant felt uncomfortable while wearing it.

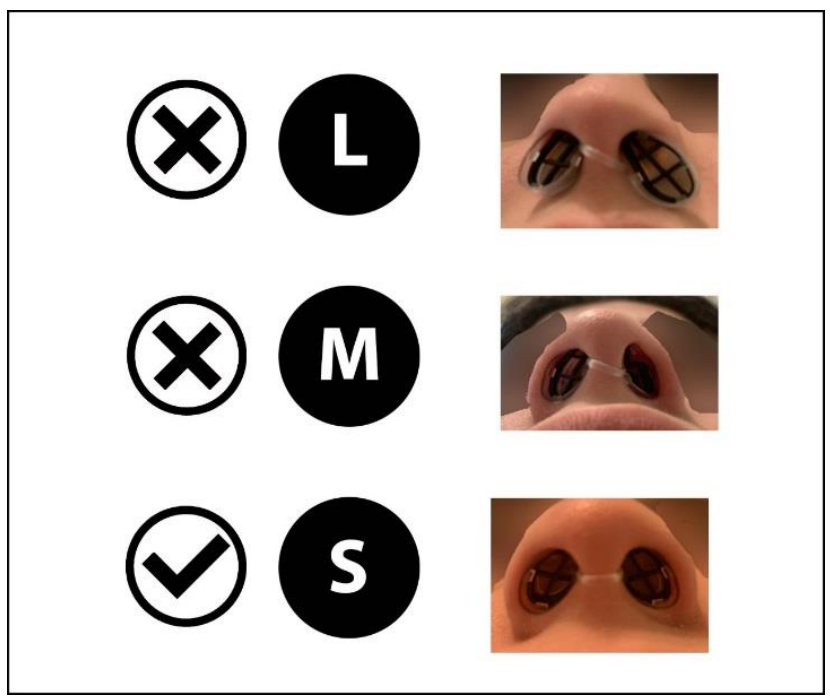

Figure 8: The appropriate nose filter size for the nostril

\subsubsection{Evaluation Parameters}

After wearing the nasal filters and performing tasks the subjects were asked to complete a qualitative evaluation. This evaluation contained six categories that measure the users' physical feelings and experience while using the nasal filter. The evaluation instrument is explained in Table 19. The scale in all categories was collected from the Borg scale and numerous research studies (Borg, 1998; MacDowell, 2018; Yang, 2019). They evaluated the comfort of a various types of respirators, including PAPRs and N95 FFR for health care workers.

Table 19: Parameters for Evaluation

\begin{tabular}{cl}
\hline \multicolumn{1}{c}{ Category } & \multicolumn{1}{c}{ Scale } \\
\hline & 1- Very Poor \\
& 2- Poor \\
& 3- Acceptable \\
General Comfort (1-6) & 4- Good \\
& 5- Very Good \\
& 6- Excellent \\
\hline
\end{tabular}




\begin{tabular}{ll}
\hline Inspiratory/expiratory & 1 - Not noticeable \\
effort (1-7) & 7- Intolerable \\
\hline & 1- Not at all \\
& 2- Very slight \\
Overall breathing & 3- Slight \\
discomfort (1-6) & 4- Somewhat high \\
& 5- High \\
& 6- Unbearable \\
\hline & 1- Not at all \\
& 2- Very slight \\
& 3- Slight \\
Pressure or pain (1-6) & 4- Somewhat high \\
& 5- High \\
& 6- Unbearable \\
\hline Exertion (6-20) & 6- No exertion at all \\
& 20- Maximal exertion \\
\hline & 1- Very Poor \\
& 2- Poor \\
& 3- Acceptable \\
& 4- Good \\
Overall assessment (1-6) & 5- Very Good \\
& 6- Excellent \\
\hline
\end{tabular}

\subsubsection{Protocol}

The procedures of the experiment were explained to the subject, and informed consent was obtained. Basic anthropometric data such as age and gender were collected, and subjects were given a $~ 3$-minute training session to become familiar with the tasks to be performed. Subjects were asked to perform various tasks while wearing the nasal filter. After that, Subjects were asked to fill out the survey on categories that correspond to the comfort and discomfort of using the nasal filter. A five-minute break was given to subjects between wearing each nasal filter. Subjects had the opportunity to see the questionnaire before signing the consent form. 


\subsection{Data Analysis}

Six categories were used to evaluate the wearer's perceptive response to using the nasal filters. Each category had five groups (five nasal filters). Because the data is categorical, nonparametric testing, specifically a Kruskal-Wallis test was used to evaluate the data. The KruskalWallis test was used to check for differences between the mean scores of the five nasal filters. These non-parametric tests were all performed using JMP version 14 (SAS Institute Inc., Cary, NC) with $\alpha$-level is set to 0.05 .

\subsection{Result and discussion:}

Five different models of nasal filters were evaluated by eight participants, using a quantitative evaluation form that covered six different categories. For each nasal filter, statistical results such as the mean, standard deviation, maximum, and minimum values for each category are listed in Table 20.

Table 20: Evaluation statistical results for all nasal filters

\begin{tabular}{|c|c|c|c|c|c|c|c|c|c|c|}
\hline \multirow{2}{*}{ Category } & \multicolumn{2}{|c|}{$\begin{array}{l}\text { Allerceptor } \\
(\text { Mean } \pm \mathrm{SD})\end{array}$} & \multicolumn{2}{|c|}{$\begin{array}{l}\text { Best Breath } \\
(\text { Mean } \pm \mathrm{SD})\end{array}$} & \multicolumn{2}{|c|}{$\begin{array}{l}\text { Eko Mask } \\
(\text { Mean } \pm \mathrm{SD})\end{array}$} & \multicolumn{2}{|c|}{$\begin{array}{c}\text { Woody } \\
\text { Knows } \\
\text { (Mean } \pm \text { SD) }\end{array}$} & \multicolumn{2}{|c|}{$\begin{array}{l}\text { Naso Filter } \\
\text { (Mean } \pm \mathrm{SD} \text { ) }\end{array}$} \\
\hline & 3 & z & 3 & 当 & 3 & 当 & 3 & 光 & 3 & 当 \\
\hline \multirow[b]{2}{*}{ General Comfort } & \multicolumn{2}{|c|}{$3.87 \pm 1.12$} & \multicolumn{2}{|c|}{$2.87 \pm 1.12$} & \multicolumn{2}{|c|}{$3.87 \pm 0.99$} & \multicolumn{2}{|c|}{$3.75 \pm 1.48$} & \multicolumn{2}{|c|}{$2.87 \pm 1.55$} \\
\hline & 5 & 2 & 4 & 1 & 5 & 2 & 6 & 2 & 5 & 1 \\
\hline \multirow{2}{*}{$\begin{array}{l}\text { Inspiratory/expiratory } \\
\text { effort }\end{array}$} & \multicolumn{2}{|c|}{$2.62 \pm 1.18$} & \multicolumn{2}{|c|}{$2.62 \pm 1.18$} & \multicolumn{2}{|c|}{$2.25 \pm 1.28$} & \multicolumn{2}{|c|}{$2.87 \pm 1.12$} & \multicolumn{2}{|c|}{$3.62 \pm 1.40$} \\
\hline & 4 & 1 & 4 & 1 & 5 & 1 & 5 & 2 & 6 & 2 \\
\hline
\end{tabular}




\begin{tabular}{|c|c|c|c|c|c|c|c|c|c|c|}
\hline \multirow{2}{*}{$\begin{array}{l}\text { Overall breathing } \\
\text { discomfort }\end{array}$} & \multicolumn{2}{|c|}{$2.75 \pm 0.70$} & \multicolumn{2}{|c|}{$3.37 \pm 1.30$} & \multicolumn{2}{|c|}{$2.37 \pm 1.06$} & \multicolumn{2}{|c|}{$2.87 \pm 1.45$} & \multicolumn{2}{|c|}{$3.00 \pm 1.30$} \\
\hline & 4 & 2 & 5 & 1 & 4 & 1 & 5 & 1 & 5 & 1 \\
\hline \multirow[b]{2}{*}{ Pressure or pain } & \multicolumn{2}{|c|}{$1.50 \pm 0.75$} & \multicolumn{2}{|c|}{$2.75 \pm 1.03$} & \multicolumn{2}{|c|}{$1.62 \pm 0.74$} & \multicolumn{2}{|c|}{$1.37 \pm 0.74$} & \multicolumn{2}{|c|}{$2.12 \pm 1.80$} \\
\hline & 3 & 1 & 4 & 2 & 3 & 1 & 3 & 1 & 5 & 1 \\
\hline \multirow{2}{*}{ Exertion } & \multicolumn{2}{|c|}{$8.00 \pm 1.60$} & \multicolumn{2}{|c|}{$9.25 \pm 2.18$} & \multicolumn{2}{|c|}{$7.50 \pm 1.92$} & \multicolumn{2}{|c|}{$8.25 \pm 1.58$} & \multicolumn{2}{|c|}{$10.12 \pm 3.44$} \\
\hline & 11 & 6 & 12 & 7 & 11 & 6 & 11 & 7 & 17 & 7 \\
\hline \multirow{2}{*}{ Overall assessment } & \multicolumn{2}{|c|}{$3.37 \pm 0.91$} & \multicolumn{2}{|c|}{$2.87 \pm 1.24$} & \multicolumn{2}{|c|}{$3.62 \pm 1.30$} & \multicolumn{2}{|c|}{$3.12 \pm 1.35$} & \multicolumn{2}{|c|}{$3.87 \pm 1.35$} \\
\hline & 5 & 2 & 5 & 1 & 5 & 2 & 5 & 1 & 6 & 3 \\
\hline
\end{tabular}

Each participant rated the filters across six categories. General comfort and total assessment categories were scaled from one to six, with six being excellent (the best) and one being very poor (the worst). Inspiratory/expiratory effort was scaled from one to seven, with one being not noticeable and seven being intolerable. Overall breathing discomfort and pressure or pain were scaled from one to six, with one being not at all and six being unbearable. The scale of exertion was from six to twenty; six was no exertion at all and twenty was maximal exertion.

As seen in Table 20, there was a small difference between nasal filters for each category. Best Breath and Naso filter types had the most exertion during walking, the highest mean reported pressure or pain discomfort, and the lowest overall mean general comfort level. The Eko Mask filter followed closely by the Allerceptor filter, had the best mean scores in all categories. The Best Breath filter had the lowest mean scores in all categories. In general, using nasal filters may increase inspiratory/expiratory effort and overall breathing discomfort, which is consistent with the study in O'Meara et al. (2005). They found that wearing a nasal filter for 60 minutes increases both inspiratory effort and nose-blowing. In Kenney et al. 's study, which included 834 participants 
during the main grass pollen season in Denmark, participants received nasal filters to use for two weeks (2014). After week one, $76 \%$ of the participants expressed interest to continue using the nasal filters for the second week, while 200 of the participants stopped using the filters for several reasons. One reason mentioned by 29 participants was that they experienced difficulty breathing when using the nasal filter.

In our study, we included a question in the evaluation about the number of hours that the participant felt they could wear the nasal filter. The maximum number of hours reported by a participant was 8 hours and the minimum for less than 1 hour. Some of the nasal filters were uncomfortable, too tight, and itchy when worn by the test subjects. The mean, standard deviation, maximal, and minimal number of hours for wearing each nasal filter are listed in Table 21. As seen in Table 21, Eko Mask filter had the largest mean number of hours (6.12 hr) that participants felt they could wear the nasal filter, while Woody Knows and Best Breath filters had the lowest mean number of hours $(3.50 \mathrm{hr})$.

Table 21: Number of hours for wearing the nasal filter

\begin{tabular}{lccc}
\hline Nasal Filter Type & (Mean \pm SD); hr & Maximum & Minimum \\
\hline Allerceptor & $4.62 \pm 2.72$ & 8 & 2 \\
Best Breath & $3.50 \pm 2.67$ & 8 & 1 \\
Eko Mask & $6.12 \pm 2.29$ & 8 & 2 \\
Woody Knows & $3.50 \pm 3.74$ & 8 & $<1$ \\
Naso Filter & $4.87 \pm 2.94$ & 8 & 1 \\
\hline
\end{tabular}

Further analysis was conducted using JMP software with a nonparametric test of KruskalWallis to check the difference between the types of nasal filter among the evaluative categories. The results from the nonparametric test are shown in Table 22. The results indicated that among all six categories (general comfort, inspiratory/expiratory effort, overall breathing discomfort, 
pressure or pain, and overall assessment), there were no differences between the models of nasal filters $(\mathrm{P}>0.05)$.

Table 22: Kruskal-Wallis test results when comparing between the nasal filters

\begin{tabular}{lccc}
\hline \multicolumn{1}{c}{ Category } & chi-squared & DF & P-value \\
\hline $\begin{array}{l}\text { General Comfort } \\
\text { Inspiratory/expiratory } \\
\text { effort }\end{array}$ & 4.8750 & 4 & 0.3004 \\
$\begin{array}{l}\text { Overall breathing } \\
\text { discomfort }\end{array}$ & 4.9586 & 4 & 0.2916 \\
Pressure or pain & 3.2544 & 4 & 0.5162 \\
$\begin{array}{l}\text { Exertion } \\
\text { Overall assessment }\end{array}$ & 9.3550 & 4 & 0.0528 \\
\hline
\end{tabular}

\subsection{Conclusion}

The Eko Mask filter was preferred over the remaining four nasal filters. It had the highest mean general comfort score, the lowest inspiratory/expiratory effort score, the lowest mean overall breathing discomfort score, and the lowest mean exertion score (Table 20). Participants preferred to wear the Eko Mask filter for more than six hours per day $(6.12 \mathrm{hr}$ ), which was the highest between all nasal filters. The difference between the mean score for all categories was relatively low among all models of nasal filters (Table 21). The results of the nonparametric test using Kruskal-Wallis indicated that there was no significant difference between the five nasal filters in all categories.

There were a few limitations in this study. One of the limitations was that the participants were completing the experiment in only ten minutes, while a worker might need to wear a nasal filter for a longer period of time, possibly up to eight hours. Also, a second limitation was related to the number of participants in this experiment. The number of participants in the experiment was eight, which is a small number compared to many other studies to measure the comfort of different 
nasal filters. Increasing experimental time and number of participants would give more accurate results that show differences between the types of nasal filters. 


\section{References:}

Achutan, C., West, C., Mueller, C., \& Boudreau, Y. (2009). Environmental and Biological Assessment of Environmental Tobacco Smoke Exposure Among Casino Dealers. National Institute for Occupational Health and Safety.

Adhikari, A., Mitra, A., Rashidi, A., Ekpo, I., Schwartz, J., \& Doehling, J. (2018). Field Evaluation of N95 Filtering Facepiece Respirators on Construction Jobsites for Protection against Airborne Ultrafine Particles. International journal of environmental research and public health, 15(9), 1958.

ANSI. (2001). Respirator Fit Testing Methods.

Babb, S., McNeil, C., Kruger, J., \& Tynan, M. A. (2015). Secondhand smoke and smoking restrictions in casinos: a review of the evidence. Tobacco control, 24(1), 11-17.

Bahl, V., Weng, N. J. H., Schick, S. F., Sleiman, M., Whitehead, J., Ibarra, A., \& Talbot, P. (2016). Cytotoxicity of thirdhand smoke and identification of acrolein as a volatile thirdhand smoke chemical that inhibits cell proliferation. Toxicological Sciences, 150(1), 234-246

Baig, A. S., Knapp, C., Eagan, A. E., \& Radonovich Jr, L. J. (2010). Health care workers' views about respirator use and features that should be included in the next generation of respirators. American journal of infection control, 38(1), 18-25.

Beder, A., Büyükkoçak, Ü., Sabuncuoğlu, H., Keskil, Z. A., \& Keskil, S. (2008). Preliminary report on surgical mask induced deoxygenation during major surgery. Neurocirugia, 19(2), $121-126$.

Bielska, D. E., Kurpas, D., Nitsch-Osuch, A., Gomolka, E., Oldak, E., Chlabicz, S., \& Owlasiuk, A. (2015). Exposure to environmental tobacco smoke and respiratory tract infections in 
pre-school choldren-a cross-sectional study in Poland. Annals of Agricultural and Environmental Medicine, 22(3).

Bigazzi, A. Y., \& Rouleau, M. (2017). Can traffic management strategies improve urban air quality? A review of the evidence. Journal of Transport \& Health, 7, 111-124.

Bischoff, W. (2017). Evaluation of a Novel Powered Air Purifying Respirator (PAPR) vs. a N95 Respirator Mask for the Protection against Influenza in a Human Exposure Model. Age, $30,31-4$.

Borg, G. (1998). Borg's perceived exertion and pain scales. Human kinetics.

Boulton, W., Lepage, M., Coulson, B., Martin, T., Hanna, E., Victor, P., ... \& Hanna, R. (2005). Cost benefit analysis: replacing Ontario's coal-fired electricity generation.

Boy, E., Bruce, N., \& Delgado, H. (2002). Birth weight and exposure to kitchen wood smoke during pregnancy in rural Guatemala. Environmental health perspectives, 110(1), 109-114.

Braun, M., Koger, F., Klingelhöfer, D., Müller, R., \& Groneberg, D. A. (2019). Particulate matter emissions of four different cigarette types of one popular brand: Influence of tobacco strength and additives. International journal of environmental research and public health, 16(2), 263.

Canner, P., \& Bakke, B. (1980). Nose or mouth breatthing. Environ Res, 21, 394-8.

Chen, S. C., Chang, D. Q., Pei, C., Tsai, C. J., \& Pui, D. Y. (2016). Removal Efficiency of bimodal PM2. 5 and PM10 by electret respirators and mechanical engine intake filters. Aerosol and Air Quality Research, 16(7), 1722-1729.

Chen, S.-C., Wang, J., Bahk, Y.K., Fissan, H. and Pui, D.Y. (2014). Carbon Nanotube Penetration through Fiberglass and Electret Respirator Filter and Nuclepore Filter Media: Experiments and Models. Aerosol Sci. Technol. 48: 997-1008. 
City of New York. PlaNYC: Progress Report 2014.

http://www.nyc.gov/html/planyc2030/downloads/pdf/140422_PlaNYCPReport_FINAL_Web.pdf

Collier, A. C., Dandge, S. D., Woodrow, J. E., \& Pritsos, C. A. (2005). Differences in DNAdamage in non-smoking men and women exposed to environmental tobacco smoke (ETS). Toxicology letters, 158(1), 10-19.

Collings, D. A., Sithole, S. D., \& Martin, K. S. (1990). Indoor woodsmoke pollution causing lower respiratory disease in children. Tropical doctor, 20(4), 151-155.

Cooper, E. A. (1960). A comparison of the respiratory work done against an external resistance by man and by a sine-wave pump. Quarterly Journal of Experimental Physiology and Cognate Medical Sciences: Translation and Integration, 45(2), 179-191.

D'Amato, G., D'amato, M., Rumi, G., Cantera, E., Cortes, M., \& Dattilo, R. (2013). Improvement of quality of life in allergic rhinoconjunctivitis patients using nasal filters, a preliminary study. Eur Ann Allergy Clin Immunol, 45(5), 167-175.

D'Amato, G., Liccardi, G., Salzillo, A., Russo, M., Narciso, P., \& Allegra, L. (2012). Nasal filters in prevention of seasonal rhinitis induced by allergenic pollen grains. Open clinical study. Eur Ann Allergy Clin Immunol, 44, 83-85.

Davidson, C. S., Green, C. F., Gibbs, S. G., Schmid, K. K., Panlilio, A. L., Jensen, P. A., \& Scarpino, P. V. (2013). Performance evaluation of selected N95 respirators and surgical masks when challenged with aerosolized endospores and inert particles. Journal of occupational and environmental hygiene, 10(9), 461-467.

Dherani, M., Pope, D., Mascarenhas, M., Smith, K. R., Weber, M., \& Bruce, N. (2008). Indoor air pollution from unprocessed solid fuel use and pneumonia risk in children aged under five 
years: a systematic review and meta-analysis. Bulletin of the World Health Organization, 86, 390-398C.

EPA, CPS. "The inside story: A guide to indoor air quality." United States (1995).

Eshbaugh, J. P., Gardner, P. D., Richardson, A. W., \& Hofacre, K. C. (2008). N95 and P100 respirator filter efficiency under high constant and cyclic flow. Journal of occupational and environmental hygiene, 6(1), 52-61.

Gaita, S. M., Boman, J., Gatari, M. J., Wagner, A., \& Jonsson, S. K. (2016). Characterization of size-fractionated particulate matter and deposition fractions in human respiratory system in a typical African city: Nairobi, Kenya. Aerosol Air Qual Res, 16, 2378-2385.

Harber, P., Santiago, S., Wu, S., Bansal, S., Liu, Y., \& Yun, D. (2010). Subjective response to respirator type: effect of disease status and gender. Journal of occupational and environmental medicine, 52(2), 150-154.

He, X., Grinshpun, S. A., Reponen, T., McKay, R., Bergman, M. S., \& Zhuang, Z. (2014). Effects of breathing frequency and flow rate on the total inward leakage of an elastomeric halfmask donned on an advanced manikin headform. Annals of occupational hygiene, 58(2), $182-194$.

He, X., Yermakov, M., Reponen, T., McKay, R. T., James, K., \& Grinshpun, S. A. (2013). Manikin-based performance evaluation of elastomeric respirators against combustion particles. Journal of occupational and environmental hygiene, 10(4), 203-212.

HINDS, W. C. (1978). Size characteristics of cigarette smoke. American Industrial Hygiene Association Journal, 39(1), 48-54.

Holman, C., Harrison, R., \& Querol, X. (2015). Review of the efficacy of low emission zones to improve urban air quality in European cities. Atmospheric Environment, 111, 161-169. 
Hu, K., Guo, Y., Hu, D., Du, R., Yang, X., Zhong, J., ... \& Yang, J. (2018). Mortality burden attributable to PM1 in Zhejiang province, China. Environment international, 121, 515-522.

Johnson, A. T. (2016). Respirator masks protect health but impact performance: a review. Journal of biological engineering, 10(1), 4.

Johnson, A. T., Mackey, K. R., Scott, W. H., Koh, F. C., Chiou, K. Y., \& Phelps, S. J. (2005). Exercise performance while wearing a tight-fitting powered air purifying respirator with limited flow. Journal of occupational and environmental hygiene, 2(7), 368-373.

Kant, N., Müller, R., Braun, M., Gerber, A., \& Groneberg, D. (2016). Particulate matter in secondhand smoke emitted from different cigarette sizes and types of the brand vogue mainly smoked by women. International journal of environmental research and public health, 13(8), 799.

Kao, T. W., Tsai, H. B., Chen, C., Chiu, M. J., Hu, F. C., \& Chen, P. C. (2010). Physiological and neuropsychological impacts of wearing an N95 mask on young medical staff. Occup Environ Med, 60(Suppl 1), A136.

Kenney, P., Hilberg, O., \& Sigsgaard, T. (2016). Clinical application of nasal filters: an observational study on the usability of nasal filters in managing seasonal allergic rhinitis. The Journal of Allergy and Clinical Immunology: In Practice, 4(3), 445-452.

Kenney, P., Hilberg, O., Laursen, A. C., Peel, R. G., \& Sigsgaard, T. (2015). Preventive effect of nasal filters on allergic rhinitis: a randomized, double-blind, placebo-controlled crossover park study. Journal of Allergy and Clinical Immunology, 136(6), 1566-1572.

Kenney, P., Hilberg, O., Pedersen, H., Nielsen, O. B., \& Sigsgaard, T. (2014). Nasal filters for the treatment of allergic rhinitis: a randomized, double-blind, placebo-controlled crossover clinical trial. Journal of allergy and clinical immunology, 133(5), 1477. 
Kleinman, M. T. (1984). Sulfur dioxide and exercise: relationships between response and absorption in upper airways. Journal of the Air Pollution Control Association, 34(1), 3237.

Klepeis, N. E., Dhaliwal, N., Hayward, G., Acevedo-Bolton, V., Ott, W. R., Read, N., ... \& Repace, J. L. (2016). Measuring indoor air quality and engaging California Indian stakeholders at the Win-River Resort and Casino: collaborative smoke-free policy development. International journal of environmental research and public health, 13(1), 143.

Le Cann, P., Bonvallot, N., Glorennec, P., Deguen, S., Goeury, C., \& Le Bot, B. (2011). Indoor environment and children's health: recent developments in chemical, biological, physical and social aspects. International journal of hygiene and environmental health, 215(1), 118.

Lee, K. W., \& Liu, B. Y. H. (1980). On the minimum efficiency and the most penetrating particle size for fibrous filters. Journal of the Air Pollution Control Association, 30(4), 377-381.

Lenhart, S. W., Seitz, T., Trout, D., \& Bollinger, N. (2004). Issues affecting respirator selection for workers exposed to infectious aerosols: emphasis on healthcare settings. Applied Biosafety, 9(1), 20-36.

Lewis, Alastair. 'Beware China's 'Anti-Smog Tower' and Other Plans to Pull Pollution from the Air.” $\quad$ https://theconversation.com/beware-chinas-anti-smog-tower-and-other-plans-topull-pollutionfrom-the-air-90596.

Li, Y., Tokura, H., Guo, Y. P., Wong, A. S. W., Wong, T., Chung, J., \& Newton, E. (2005). Effects of wearing N95 and surgical facemasks on heart rate, thermal stress and subjective sensations. International archives of occupational and environmental health, 78(6), 501509. 
Lim, E. C. H., Seet, R. C. S., Lee, K. H., Wilder-Smith, E. P. V., Chuah, B. Y. S., \& Ong, B. K. C. (2006). Headaches and the N95 face-mask amongst healthcare providers. Acta Neurologica Scandinavica, 113(3), 199-202.

Lim, S. S., Vos, T., Flaxman, A. D., Danaei, G., Shibuya, K., Adair-Rohani, H., ... \& Aryee, M. (2012). A comparative risk assessment of burden of disease and injury attributable to 67 risk factors and risk factor clusters in 21 regions, 1990-2010: a systematic analysis for the Global Burden of Disease Study 2010. The lancet, 380(9859), 2224-2260.

Liverman, C. T., \& Goldfrank, L. R. (Eds.). (2007). Preparing for an influenza pandemic: Personal protective equipment for healthcare Workers. National Academies Press.

Locatelli, S. M., LaVela, S. L., \& Gosch, M. (2014). Health care workers' reported discomfort while wearing filtering face-piece respirators. Workplace health \& safety, 62(9), 362-368.

Losonczy, G. (2012). Small (<2.5 micron) Particulate Matter Concentration of Ambient Air and Early Death in Hungary. Orvosi Hetilap 153(8), 285-288

Lumb, A. B. (2016). Nunn's applied respiratory physiology eBook. Elsevier Health Sciences.

Lundberg, J. O. (2008). Nitric oxide and the paranasal sinuses. The Anatomical Record: Advances in Integrative Anatomy and Evolutionary Biology: Advances in Integrative Anatomy and Evolutionary Biology, 291(11), 1479-1484.

MacDowell, L. (2018). Preference and user experience with powered air-purifying respirators in healthcare workers in a simulated work environment: a pilot study.

Matt, G. E., Quintana, P. J., Hoh, E., Zakarian, J. M., Chowdhury, Z., Hovell, M. F., ... \& Nguyen, A. (2018). A Casino goes smoke free: a longitudinal study of secondhand and thirdhand smoke pollution and exposure. Tobacco control, 27(6), 643-649. 
Max, W., Sung, H. Y., \& Shi, Y. (2012). Deaths from secondhand smoke exposure in the United States: economic implications. American journal of public health, 102(11), 2173-2180.

Meister, A. (2005). Indian gaming industry report. Casino City Press.

Mendell, M. J., Fisk, W. J., Kreiss, K., Levin, H., Alexander, D., Cain, W. S., ... \& Rexroat, L. P. (2002). Improving the health of workers in indoor environments: priority research needs for a national occupational research agenda. American journal of public health, 92(9), 1430-1440.

Mukhametzanov, I.T., Grinshpun, S.A., Zaripov, S.K. and Gilfanov, A.K. (2016). Assessing the Protection Provided by Facepiece Filtering Respirator: New Model Involving Spherical Porous Layer with Annular Peripheral Opening. Aerosol Air Qual. Res. 16: 2428-2437.

Myers, A. (2011, March 25). Secondhand smoke raises the stakes in America's casinos. Retrieved from https://news.stanford.edu/news/2011/march/casino-secondhand-smoke-032511.html

National Institute for Occupational Safety and Health (NIOSH). 42 CFR Part 84 Respiratory Protective Devices (1995) Final Rules and Notice. Federal Register 60: 30336-30402.

National Research Council. (1986). Environmental tobacco smoke: measuring exposures and assessing health effects. National Academies Press.

Noback, M. L., Harvati, K., \& Spoor, F. (2011). Climate-related variation of the human nasal cavity. American journal of physical anthropology, 145(4), 599-614.

Öberg, M., Jaakkola, M. S., Woodward, A., Peruga, A., \& Prüss-Ustün, A. (2011). Worldwide burden of disease from exposure to second-hand smoke: a retrospective analysis of data from 192 countries. The lancet, 377(9760), 139-146.

Occupational Safety and Health Administration. Respiratory Protection. 2002. 
O'Meara, T. J., Sercombe, J. K., Morgan, G., Reddel, H. K., Xuan, W., \& Tovey, E. R. (2005). The reduction of rhinitis symptoms by nasal filters during natural exposure to ragweed and grass pollen. Allergy, 60(4), 529-532.

Overton, J. R. (1973). Filtration of cigarette smoke: Relative contributions of inertial impaction, diffusional deposition, and direct interception. Beiträge zur Tabakforschung International/Contributions to Tobacco Research, 7(3), 117-120.

Palmiero, A. J., Symons, D., Morgan III, J. W., \& Shaffer, R. E. (2016). Speech intelligibility assessment of protective facemasks and air-purifying respirators. Journal of occupational and environmental hygiene, 13(12), 960-968.

Pasricha, J. S. (1981). Use of nasal filters in naso-bronchial allergy. The Indian Journal of Pediatrics, 48(1), 47-50.

Patterson, R. F., Zhang, Q., Zheng, M., \& Zhu, Y. (2014). Particle deposition in respiratory tracts of school-aged children. Aerosol Air Qual. Res, 14, 64-73.

Pérez-Padilla, R., Schilmann, A., \& Riojas-Rodriguez, H. (2010). Respiratory health effects of indoor air pollution. The International Journal of Tuberculosis and Lung Disease, 14(9), 1079-1086.

Pilkington, P. A., Gray, S., \& Gilmore, A. B. (2007). Health impacts of exposure to second hand smoke (SHS) amongst a highly exposed workforce: survey of London casino workers. BMC Public Health, 7(1), 257.

Polichetti, G., Cocco, S., Spinali, A., Trimarco, V., \& Nunziata, A. (2009). Effects of particulate matter (PM10, PM2. 5 and PM1) on the cardiovascular system. Toxicology, 261(1-2), 1-8. 
Pope 3rd, C. A., Eatough, D. J., Gold, D. R., Pang, Y., Nielsen, K. R., Nath, P., ... \& Kanner, R. E. (2001). Acute exposure to environmental tobacco smoke and heart rate variability. Environmental health perspectives, 109(7), 711-716.

Pope Iii, C. A., Burnett, R. T., Thun, M. J., Calle, E. E., Krewski, D., Ito, K., \& Thurston, G. D. (2002). Lung cancer, cardiopulmonary mortality, and long-term exposure to fine particulate air pollution. Jama, 287(9), 1132-1141.

Pope, D. P., Mishra, V., Thompson, L., Siddiqui, A. R., Rehfuess, E. A., Weber, M., \& Bruce, N. G. (2010). Risk of low birth weight and stillbirth associated with indoor air pollution from solid fuel use in developing countries. Epidemiologic reviews, 32(1), 70-81.

Powell, J. B., Kim, J. H., \& Roberge, R. J. (2017). Powered air-purifying respirator use in healthcare: Effects on thermal sensations and comfort. Journal of occupational and environmental hygiene, 14(12), 947-954.

Purdy, M. (2019). Comparison of facemask characteristics with user assessment of comfort.

Radonovich, L. J., Cheng, J., Shenal, B. V., Hodgson, M., \& Bender, B. S. (2009). Respirator tolerance in health care workers. JAMA, 301(1), 36-38.

Rebmann, T., Carrico, R., \& Wang, J. (2013). Physiologic and other effects and compliance with long-term respirator use among medical intensive care unit nurses. American journal of infection control, 41(12), 1218-1223.

Rengasamy, S., \& Eimer, B. C. (2011). Total inward leakage of nanoparticles through filtering facepiece respirators. Annals of occupational hygiene, 55(3), 253-263.

Repace, J. L. (2009). Secondhand smoke in Pennsylvania Casinos: a study of nonsmokers' exposure, dose, and risk. American journal of public health, 99(8), 1478-1485. 
Repace, J. L., \& Lowrey, A. H. (1993). An Enforceable Indoor Air Quality Standard for Environmental Tobacco Smoke in the Workplace 1. Risk Analysis, 13(4), 463-475.

Repace, J. L., Jiang, R. T., Acevedo-Bolton, V., Cheng, K. C., Klepeis, N. E., Ott, W. R., \& Hildemann, L. M. (2011). Fine particle air pollution and secondhand smoke exposures and risks inside 66 US casinos. Environmental Research, 111(4), 473-484.

Richardson, A., \& Hofacre, K. (2010). Comparison of Filtration Efficiency of a N95 Filtering Facepiece Respirator and Surgical Mask Against Viral Aerosols: Presentation Number 3013. Ajic (american Journal of Infection Control), 38(5)

Roberge, R. J., Kim, J. H., \& Benson, S. M. (2012). Absence of consequential changes in physiological, thermal and subjective responses from wearing a surgical mask. Respiratory physiology \& neurobiology, 181(1), 29-35.

Roberge, R., Benson, S., \& Kim, J. H. (2012). Thermal burden of N95 filtering facepiece respirators. Annals of occupational hygiene, 56(7), 808-814.

Robin, L. F., Lees, P. S., Winget, M., Steinhoff, M., Moulton, L. H., Santosham, M., \& Correa, A. (1996). Wood-burning stoves and lower respiratory illnesses in Navajo children. The Pediatric infectious disease journal, 15(10), 859-865.

Samet, J. M., Bahrami, H., \& Berhane, K. (2016). Indoor air pollution and cardiovascular disease: new evidence from Iran.

Sapkota, A., Gajalakshmi, V., Jetly, D. H., Roychowdhury, S., Dikshit, R. P., Brennan, P., ... \& Boffetta, P. (2008). Indoor air pollution from solid fuels and risk of hypopharyngeal/laryngeal and lung cancers: a multicentric case-control study from India. International journal of epidemiology, 37(2), 321-328. 
Singh, S., Sharma, B. B., Salvi, S., Chhatwal, J., Jain, K. C., Kumar, L., ... \& Rego, S. (2018). Allergic rhinitis, rhinoconjunctivitis, and eczema: prevalence and associated factors in children. The clinical respiratory journal, 12(2), 547-556.

Sleiman, M., Logue, J. M., Luo, W., Pankow, J. F., Gundel, L. A., \& Destaillats, H. (2014). Inhalable constituents of thirdhand tobacco smoke: chemical characterization and health impact considerations. Environmental science \& technology, 48(22), 13093-13101.

Spegele, B. (2015, July 20). China War on Pollution Benefits from Economic Slowdown. Wall Street Journal.

Steelnack, J.(2007). Assigned Protection Factor (APF) Table Added to OSHA's Respiratory Protection https://www.aiha.org/aihce07/handouts/rt243steelnack.pdfStandard 29 CFR 1910.134 .

Suri, M. (2017). Delhi tests water cannons to combat deadly air pollution. CNN.com Retrieved from https://edition.cnn.com/2017/12/22/health/india-new-delhi-water-cannon-pollutionintl/index.html.

Szeinuk, J., Beckett, W. S., Clark, N., \& Hailoo, W. L. (2000). Medical evaluation for respirator use. American journal of industrial medicine, 37(1), 142-157.

Talaat, H. S., Metwaly, M. A., Khafagy, A. H., \& Abdelraouf, H. R. (2014). Does passive smoking induce sensorineural hearing loss in children? International journal of pediatric otorhinolaryngology, 78(1), 46-49.

Travis, F., Blasdell, K., Liptak, R., Zisman, S., Daley, K., \& Douillard, J. (1996). Invincible Athletics program: Aerobic exercise and performance without strain. International Journal of Neuroscience, 85(3-4), 301-308. 
Treyster, Z., \& Gitterman, B. (2011). Second hand smoke exposure in children: environmental factors, physiological effects, and interventions within pediatrics. Reviews on environmental health, 26(3), 187-195.

US Department of Health and Human Services. (2014). The health consequences of smoking — 50 years of progress: a report of the Surgeon General.

Wang, A., Richardson, A. W., \& Hofacre, K. C. (2012). The effect of flow pattern on collection efficiency of respirator filters. Journal of the International Society of Respiratory Protection, 29(1), 41.

Wang, Q., Golshahi, L. and Chen, D.-R. (2017). Evaluation of Respirator Filter Media under Inhalation-Only Conditions. Aerosol Air Qual. Res. 17: 2681-2690.

World Health Organization. (2007). Indoor air pollution from solid fuels and risk of low birth weight and stillbirth: report from a symposium held at the Annual Conference of the International Society for Environmental Epidemiology (ISEE), September 2005, Johannesburg.

World Health Organization. (2016). Ambient air pollution: A global assessment of exposure and burden of disease.

Xie, T. (2018, July). Indoor air pollution and control technology. In IOP Conference Series: Earth and Environmental Science (Vol. 170, No. 3, p. 032084). IOP Publishing.

Yang, B. Y., Guo, Y., Morawska, L., Bloom, M. S., Markevych, I., Heinrich, J., ... \& Chen, G. (2019). Ambient PM1 air pollution and cardiovascular disease prevalence: Insights from the 33 Communities Chinese Health Study. Environment international, 123, 310-317. 
Yang, H. (2019). Performance Study of an Unconventional Breathresponse PAPR Against a N95 FFR and Conventional PAPRs

Zhou, Y. and Cheng, Y.S. (2016). Evaluation of N95 Filtering Facepiece Respirators Challenged with Engineered Nanoparticles. Aerosol Air Qual. Res. 16: 212-220.

Zhu, J. H., Lee, S. J., Wang, D. Y., \& Lee, H. P. (2014). Effects of long duration wearing of N 95 respirator and surgical facemask: a pilot study. Journal of Lung, Pulmonary and Respiratory Research, 1(4). 
Appendix A: Probability Plots, Normality Check 


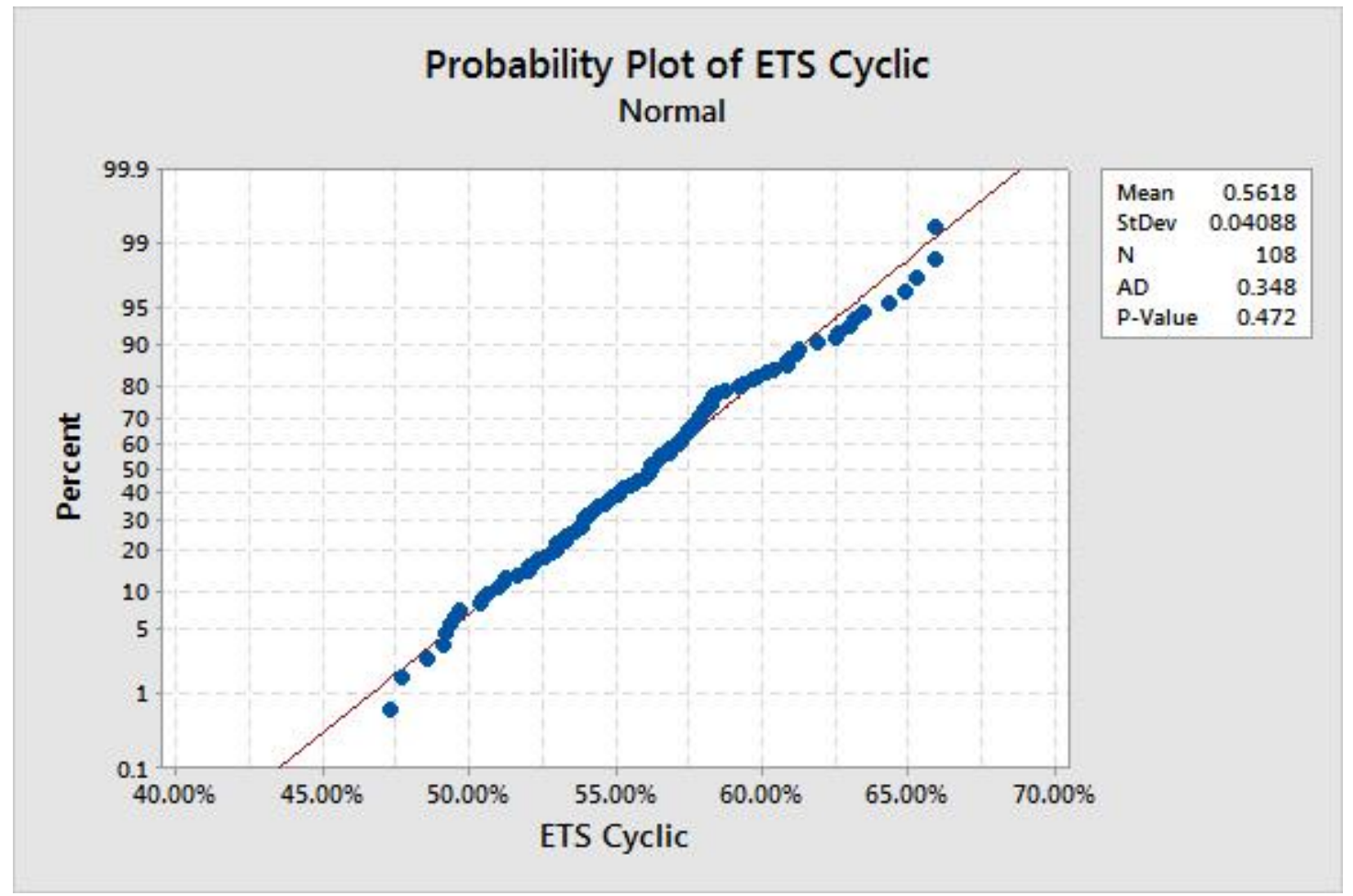

Normal Quantile Plot for ETS under cyclic flow

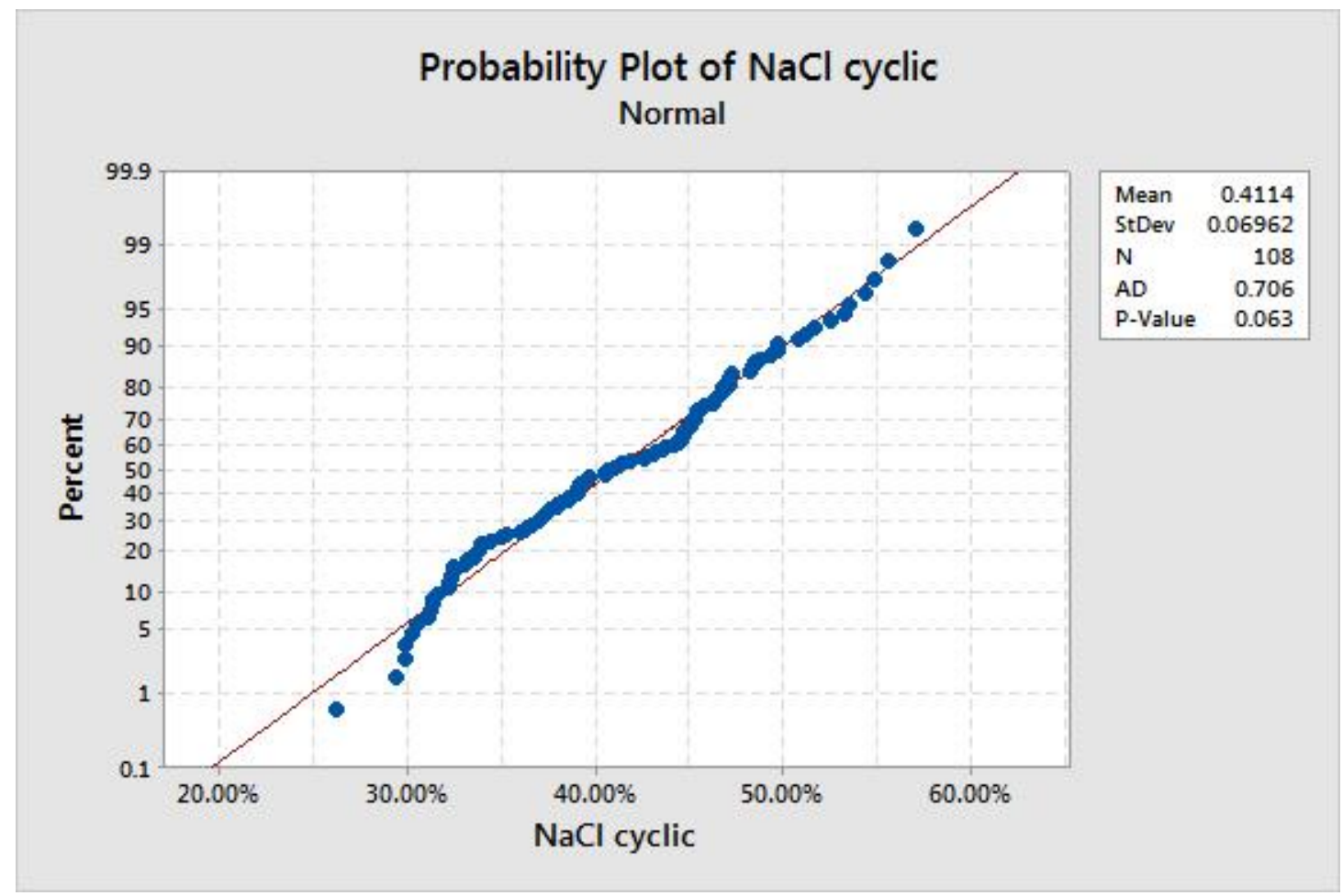

Normal Quantile Plot for $\mathrm{NaCl}$ under cyclic flow 


\section{Appendix B: Johnson Transformation}




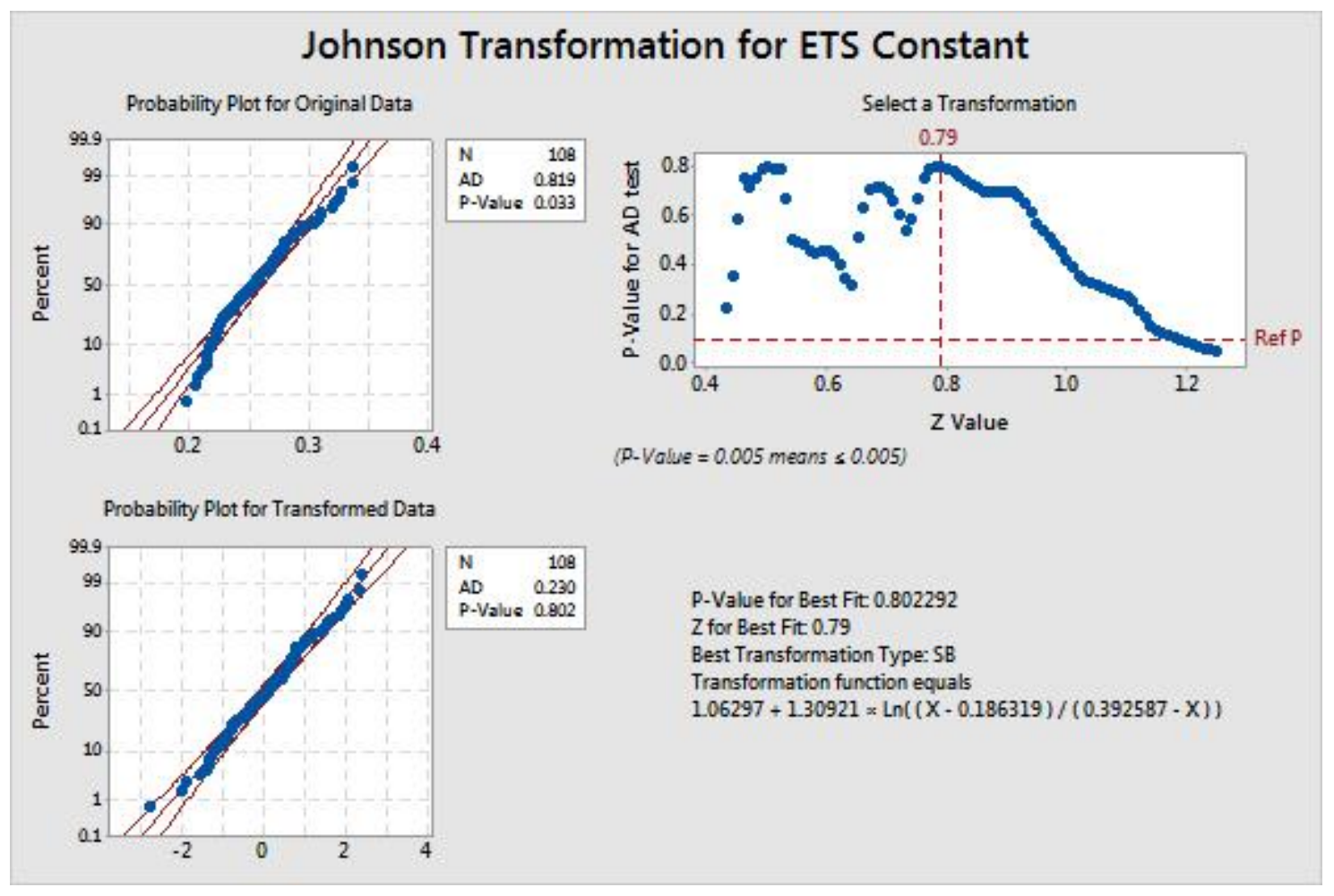

Johnson Transformation for ETS under constant flow

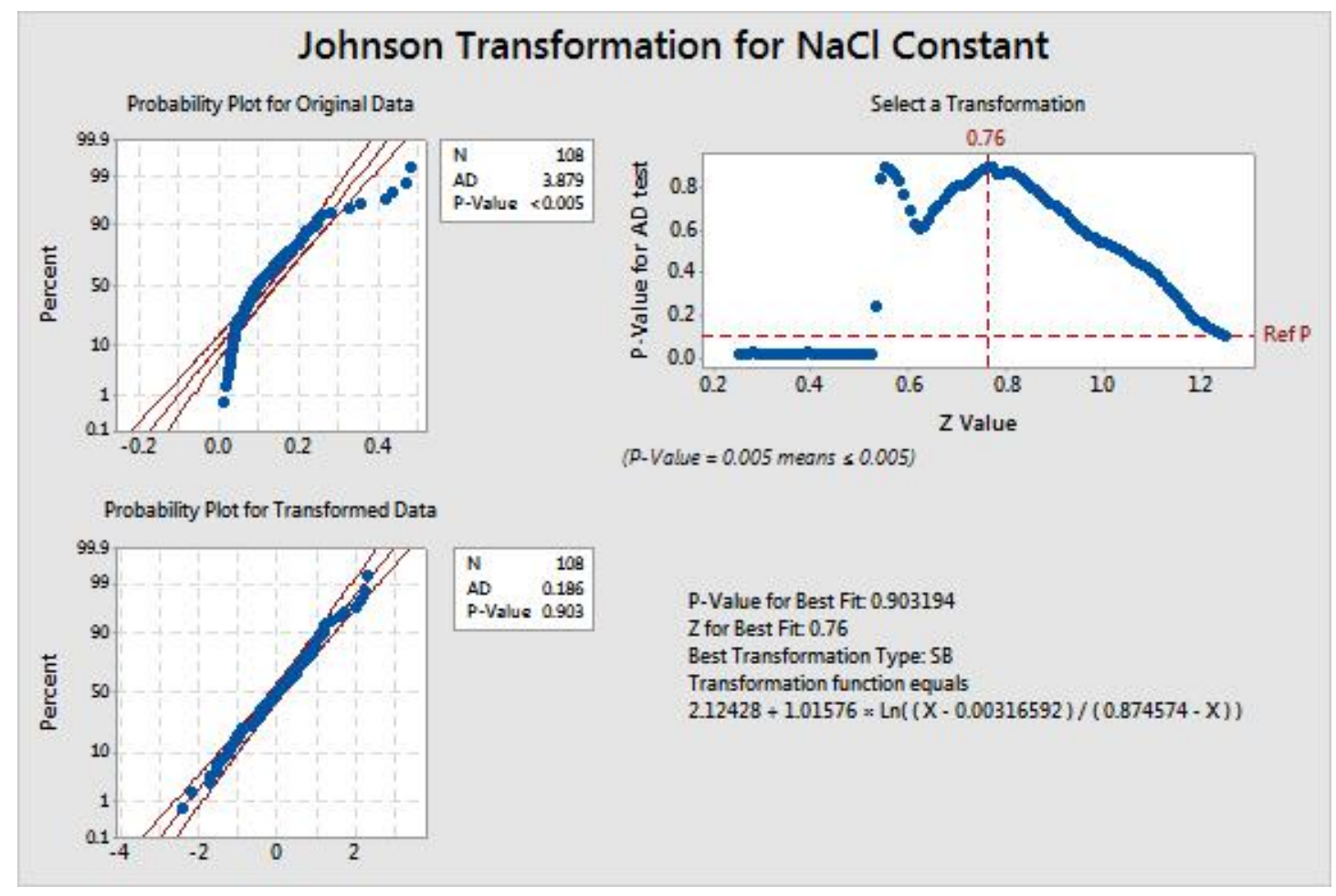

Johnson Transformation for $\mathrm{NaCl}$ under constant flow 